\title{
Guía de atención integral con evaluación económica para la prevención, el diagnóstico, el tratamiento y el seguimiento del cáncer de piel no melanoma: carcinoma escamocelular
}

Comprehensive Guide, with economic assessment, for the prevention, diagnosis, treatment and monitoring of non melanoma skin cancer: squamous cell carcinoma

\section{Álvaro Acosta', Xavier Rueda ${ }^{2}$, Guillermo Sánchez ${ }^{3}$, Ingrid Arévalo ${ }^{4}$, Hugo Eduardo Herrera $^{5}$, Ana Francisca Ramírez ${ }^{6}$, Guillermo Jiménez ${ }^{7}, 0$ mar Darío Segura ${ }^{8}$, Magda Cepeda $^{9}$, Andrea Esperanza Rodríguez ${ }^{10}$, John Alexander Nova ${ }^{11}$, Martha Cecilia Valbuena ${ }^{12}$}

1. Médico dermatólogo oncólogo; coordinador, Dermatología Oncológica, Instituto Nacional de Cancerología; profesor titular, Universidad Nacional de Colombia, Bogotá, D.C., Colombia

2. Médico dermatólogo oncólogo, Instituto Nacional de Cancerología Bogotá, D.C., Colombia

3. Médico, especialista en Epidemiología General, magíster en Epidemiología Clínica, doctor en Salud Pública, Fundación Universitaria de Ciencias de la Salud, Bogotá, D.C., Colombia

4. Médica, magíster en Epidemiología Clínica y PhD (c) en Medicina Preventiva y Salud Pública, Fundación Universitaria de Ciencias de la Salud, Bogotá, D.C., Colombia

5. Médico dermatólogo, Asociación Colombiana de Dermatología y Cirugía Dermatológica y Universidad El Bosque, Bogotá, D.C., Colombia

6. Médica dermatóloga, especialista en Dermatología Oncológica, Asociación Colombiana de Dermatología y Cirugía Dermatológica, Bogotá, D.C., Colombia

7. Médico dermatólogo, especialista en Dermatología Oncológica y Cirugía Dermatológica, Asociación Colombiana de Dermatología y Cirugía Dermatológica, Bogotá, D.C., Colombia

8. Médico, magíster en Epidemiología Clínica, Epidemiólogo de Campo, PhD (c) en Salud Pública, Fundación Universitaria de Ciencias de la Salud, Bogotá, D.C., Colombia

9. Médica, magíster en Epidemiología Clínica, Fundación Universitaria de Ciencias de la Salud, Bogotá, D.C., Colombia

10. Médica, especialista en Estadística Aplicada, magíster en Epidemiología Clínica, Fundación Universitaria de Ciencias de la Salud, Bogotá, D.C., Colombia

11. Médico dermatólogo, magíster en Epidemiología Clínica, Centro Dermatológico Federico Lleras Acosta Bogotá, D.C., Colombia

12. Médica, especialista en Dermatología y Fotodermatología, Centro Dermatológico Federico Lleras Acosta, Bogotá, D.C., Colombia

\section{RESUMEN}

OBJETIVO: Generar recomendaciones para la prevención, el diagnóstico, el tratamiento y el seguimiento del cáncer de piel no melanoma: carcinoma escamocelular, con el fin de apoyar al personal de salud en los diferentes servicios encargados de la atención de los pacientes con esta enfermedad, buscando garantizar una atención integral, homogénea, con calidad, equidad y eficiencia; además, generar indicadores de seguimiento a las recomendaciones de la guía, acordes con el contexto nacional.

MATERIALES Y MÉTODOS: Se conformó el Grupo Desarrollador de la Guía con un grupo interdisciplinario de profesionales y representantes de los pacientes. Se establecieron el alcance, los objetivos, las preguntas y los resultados de la guía. Se hizo una búsqueda de guías sobre manejo de carcinoma escamocelular, pero ninguna de
Correspondencia:

Álvaro Acosta

Email:

aeacostam@unal.edu.co

Recibido: 4 de marzo de 2015 Aceptado: 5 de mayo de 2015 
las guías encontradas podía adaptarse, por lo que se decidió desarrollar una nueva guía. Se hizo una búsqueda bibliográfica de revisiones sistemáticas, metaanálisis, ensayos clínicos, estudios de cohorte, y estudios de casos y controles, en las bases de datos Medline (vía Pubmed y Ovid), Embase y Central (vía Ovid). Se evaluó la calidad metodológica de los artículos seleccionados. Posteriormente, se elaboraron las tablas de evidencia por medio del software GRADEpro ${ }^{\circledR} 3.6$ y se generaron las recomendaciones bajo la metodología GRADE mediante consensos de expertos.

RESULTADOS: Se presentan las recomendaciones de prevención primaria, prevención secundaria, tratamiento (quirúrgico y no quirúrgico) y seguimiento del carcinoma escamocelular. Además, se presentan varias preguntas generales que sirven al lector para contextualizarse en el tema de la guía de práctica clínica, pero que no generan recomendaciones.

CONCLUSIONES: Se considera que las recomendaciones relacionadas con prevención son prioritarias en el proceso de implementación de la guía. Se presentan cuatro indicadores de auditoría para la guía de práctica clínica, relacionados con prevención, diagnóstico y tratamiento.

PALABRAS CLAVE: Guía; Carcinoma de Células Escamosas; Neoplasias Cutáneas.

\section{SUMMARY}

OBJECTIVE: To generate recommendations for the prevention, diagnosis, treatment and follow-up for the non-melanoma squamous cell carcinoma with the aim of providing support for the health professionals in the different services in charge of its attention, looking to guarantee integral, homogeneous attention, with quality, equity and efficiency for the patients with this pathology; as well as generating follow-up indicators to the guide's recommendation in accordance with the national context.

MATERIALS AND METHODS: The Guide Development Group (GDG) was formed by an interdisciplinary group of professionals and patient representatives. Reach, objectives, questions, and outcomes for the guide were defined. A guide search about handling squamous cell carcinoma was performed, but none of the guides found was found to be adaptable, therefore writing a guide de novo was decided. A literature search was performed, including systematic reviews-meta-analyses, clinical trials, cohort studies, and case-control studies in the Medline (via Pubmed and Ovid), Embase and Central (via Ovid) databases. The methodological quality of the selected articles was evaluated. Subsequently, evidence tables were made through the GRADEpro ${ }^{\circledR} 3.6$ software and recommendations were generated under the GRADE technology through experts' consensus.

RESULTS: Primary prevention, secondary prevention, treatment (surgical and nonsurgical) as well as squamous cell carcinoma follow-up recommendations are presented. Additionally, several general questions are presented which serve the reader to be contextualized in the subject of CPG, but which do not generate recommendations.

CONCLUSIONS: It is considered that the recommendations relating to prevention are a priority in the guide's implementation process. Four auditing indicators for the CPG are presented relating to prevention, diagnosis, and treatment.

KEYWORDS: Guideline; Carcinoma, Squamous Cell; Skin Neoplasm.

\section{Conflictos de interés:}

A partir del momento en el que se estructuró la propuesta y se conformó el Grupo Desarrollador de la Guía, se declararon y evaluaron los posibles conflictos de intereses. Una vez la propuesta fue aprobada para su ejecución, nuevamente, y basados en lo planteado por la "Guía metodológica para la elaboración de guías de práctica clínica con evaluación económica en el Sistema General de Seguridad Social en Salud colombiano" del Ministerio de Salud y Protección Social, el grupo de expertos clínicos, expertos en metodología y el equipo de evaluación económica revisaron y declararon sus posibles conflictos de intereses. Un comité ad hoc revisó cada caso y se pronunció frente al particular. Los detalles se presentan en la versión completa de la presente guía.

\section{Agradecimiento especial a los Doctores:}

\section{Mariam Carolina Rolón}

Especialista en Dermatopatología y Patología Oncológica, Instituto Nacional de Cancerología, Bogotá, D.C., Colombia.

\section{Enrique Cadena}

Especialista en Cirugía de Cabeza y Cuello, Instituto Nacional de Cancerología, Bogotá, D.C., Colombia.

\section{Victoria Eugenia Franco}

Especialista en Dermatología, Centro Dermatológico Federico Lleras Acosta, Bogotá, D.C., Colombia. 


\section{PROPÓSITO Y ALCANCE}

La presente guía de práctica clínica, tiene como objetivo ofrecer recomendaciones basadas en la 'evidencia' para la prevención, la detección, el tratamiento y el seguimiento del carcinoma escamocelular de piel, con el fin de apoyar al personal de salud en los diferentes niveles de atención, buscando garantizar una atención integral, homogénea, con calidad, equidad y eficiencia para los pacientes con esta condición.

Esta guía de práctica clínica está dirigida al personal clínico asistencial que brinda cuidados a pacientes en la prevención, la detección temprana y la atención del carcinoma escamocelular de piel, en los diferentes grados de complejidad de los servicios de la atención en salud en el marco del Sistema General de Seguridad Social en Salud (SGSSS) (médicos familiares, médicos generales, médicos rurales, médicos especialistas en dermatología, oncólogos, cirujanos plásticos, patólogos, radioterapeutas, cirujanos de cabeza y cuello, profesionales de enfermería y otros profesionales de la salud relacionados con el manejo del carcinoma escamocelular). El manejo de condiciones específicas por parte del subespecialista, amerita recomendaciones que exceden el alcance del presente documento. De manera indirecta, esta guía de práctica clínica se dirige a tomadores de decisiones, generadores de políticas de salud, pagadores del gasto y todo el personal relacionado, que se desempeñe en el ámbito hospitalario o de las aseguradoras en salud. Ofrece recomendaciones específicas para las preguntas establecidas, y excede el alcance de la guía, definir las competencias profesionales del equipo involucrado en el manejo de esta enfermedad. Establece recomendaciones que pueden ser utilizadas en los diferentes grados de complejidad de los servicios encargados de la atención, dentro del SGSSS colombiano.

El presente documento presenta un resumen de la información contenida en la guía de práctica clínica en versión completa, la cual puede ser consultada en la página del Ministerio de Salud y Protección Social (http://gpc. minsalud.gov.co/Pages/Default.aspx).

\section{INTRODUCCIÓN Y JUSTIFICACIÓN DE LA GUIIA}

El cáncer de piel no melanoma es la enfermedad tumoral maligna más común en sujetos de raza blanca. El cáncer de piel no melanoma de tipo escamocelular es un tumor más agresivo que el carcinoma basocelular, con mayor capacidad de generar metástasis y, por lo tanto, de mayor mortalidad. En general, se han identificado mutaciones en los genes $p_{53}$ y $p_{16^{1,2}}$. La mayor parte de los procesos descritos relacionados con la génesis del cáncer de piel no melanoma, son producto de alteraciones complejas que involucran daños en la capacidad de reparación del $\mathrm{ADN}$, principalmente asociados con la exposición cutánea a la radiación ultravioleta ${ }^{3-6}$.

Existe una clara tendencia hacia un incremento en el número de casos a nivel mundial, siendo Australia el país con mayor incidencia de cáncer de piel en el mundo. En el 2002, la incidencia global del cáncer de piel no melanoma fue de 1.170 por 100.000 habitantes, mientras la incidencia del carcinoma escamocelular fue de 387 por 100.000 habitantes $^{7-10}$. En Estados Unidos, se diagnostican anualmente 3,5 millones de cánceres de piel no melanoma, de los cuales $20 \%$ corresponden a carcinoma escamocelular, para una incidencia de 290 casos por 100.000 habitantes. En el Reino Unido, se estima que la incidencia es cercana a 22,65 casos por 100.000 personas al año, con una tendencia creciente en toda Europa ${ }^{11}$, mientras que en Canadá, en el 2006, se registraron 60,2 casos nuevos por 100.000 habitantes al año ${ }^{11}$. En Colombia, se estimó una incidencia de cáncer de piel no melanoma de 34 por 100.000 habitantes para el año $2007^{12}$.

En Colombia existen dos instituciones del orden nacional, consideradas centros de referencia para el diagnóstico y el tratamiento del cáncer de piel: el Instituto Nacional de Cancerología y el Centro Dermatológico Federico Lleras Acosta; en estos hospitales se ha documentado un incremento progresivo del número de casos. Según los datos del Anuario Estadístico 2010 del Instituto Nacional de Cancerología, el cáncer de piel es responsable del 20,2 \% del total de casos de cáncer atendidos por esta entidad, siendo la enfermedad tumoral maligna más frecuente ${ }^{13}$. Nova, et al., publicaron el perfil epidemiológico de los pacientes con cáncer de piel en el Centro Dermatológico Federico Lleras Acosta; describieron un número creciente de casos en relación con el número de pacientes con enfermedad cutánea atendidos en este centro, pasando de 6 por 1.000 en el 2003, a 17 por 1.000 en el $2005^{14}$. Asimismo, un estudio publicado por Sánchez, et al., en el 2011, permitió establecer, con datos de población, la incidencia de cáncer de piel en Colombia y documentó un incremento significativo, pasando de 23 casos por 100.000 habitantes en el 2003, a 41 casos por 100.000 habitantes en el $2007^{12}$. Estas cifras llevan a priorizar el cáncer de piel, debido a la gran carga para la salud de la población, los efectos sobre la calidad de vida, los costos potenciales para el sistema de salud y el excelente pronóstico clínico que tienen las lesiones premalignas, como la queratosis actínica.

En este contexto, el Ministerio de Salud y Protección Social ha encargado a la Fundación Universitaria de 
Ciencias de la Salud, en conjunto con el Instituto Nacional de Cancerología y el Centro Dermatológico Federico Lleras, el desarrollo de una guía de práctica clínica sobre el manejo del carcinoma escamocelular. Esta guía de práctica clínica basada en la evidencia, puede ofrecer a los ciudadanos y al personal asistencial, las mejores alternativas de prevención, diagnóstico, tratamiento y seguimiento del carcinoma de piel no melanoma de tipo escamocelular. Las guías clínicas del Ministerio, una vez publicadas, serán la referencia para la aplicación de procesos asistenciales en instituciones de primer, segundo y tercer nivel de atención. Las declaraciones contenidas para cada proceso, reflejan la evidencia científica utilizada cuando se desarrollaron.

Por otra parte, si bien es importante reconocer que, aunque el cáncer de piel puede ser una enfermedad que tratada a tiempo tiene complicaciones mínimas y un bajo potencial de letalidad ${ }^{15}$, cuando existen barreras para el acceso a los servicios de salud ${ }^{16}$, puede presentar un curso completamente diferente, lo cual modifica sustancialmente el desenlace final. El cáncer de piel es una enfermedad producto de múltiples interacciones ambientales, genéticas, sociales, culturales y políticas, que debe ser abordado para su tratamiento por un sistema de salud, que debe ser capaz, a la luz de los conocimientos y los avances tecnológicos del siglo XXI, de resolver satisfactoriamente y en corto tiempo un alto porcentaje de los casos que se presentan ${ }^{17}$.

La presente guía busca ser una herramienta de ayuda para el personal de salud, los pacientes y las demás partes involucradas en la prestación de los servicios de salud. En ella se incluyen temas que abarcan desde las manifestaciones clínicas de la enfermedad hasta los tratamientos y seguimientos recomendados según la evidencia disponible al momento de su desarrollo, haciéndose énfasis especial en la prevención de la enfermedad.

\section{MATERIALES Y MÉTODOS}

El grupo desarrollador de la guía para la prevención, el diagnóstico, el tratamiento y el seguimiento del cáncer de piel: carcinoma escamocelular, siguió los lineamientos presentados por la guía metodológica para la elaboración de guías de práctica clínica con evaluación económica en el SGSSS colombiano desarrollada por el Ministerio de Salud y Protección Social junto con Colciencias, el Centro de Estudios e Investigación en Salud de la Fundación Santafé de Bogotá y la Escuela de Salud Pública de la Universidad de Harvard ${ }^{18,19}$. Este grupo fue conformado por expertos temáticos adscritos a sociedades científicas e incluyó dermatólogos, der- matooncólogos, dermatopatólogos, enfermeras, epidemiólogos clínicos, salubristas y representantes de los pacientes, así como expertos en economía de la salud para desarrollar las evaluaciones económicas de la guía de práctica clínica. Todos los profesionales incluidos cumplieron con la declaración de conflicto de intereses. Los representantes de los pacientes participaron en las diferentes fases del proceso de construcción de la guía de práctica clínica.

Una vez formuladas las preguntas clínicas, el grupo desarrollador de la guía procedió a hacer una búsqueda sistemática de guías de práctica clínica, orientada a identificar las guías nacionales e internacionales disponibles entre el 2000 y el 2013, de acuerdo con lo sugerido por el Manual Metodológico del Sistema Nacional de Salud de España ${ }^{20}$. Los sitios consultados fueron: AHRQ National Guidelines Clearinghouse, NHS National Library of Guidelines, GuiaSalud, Scottish Intercollegiate Guidelines Network, National Institute for Clinical Excellence, Australian National Health and Medical Research Council, New Zealand Guidelines Group, Geneva Foundation for Medical Education and Research, Organización Mundial de la Salud (OMS), Organización Panamericana de la Salud (OPS), ICSI Health Care Guidelines, Singapore MoH Guidelines Project, TRIP database, Excelencia Clínica, Medline a través de PubMed, Embase a través de Ovid y Lilacs a través de BVS. En el caso de la presente guía de práctica clínica, si bien se identificaron referencias en la búsqueda bibliográfica de guías, estas no proporcionaban evidencia bajo un proceso sistemático de búsquedas bibliográficas, ni presentaban información sobre la valoración de la evidencia por medio de un método sistemático que permitiese la generación transparente de recomendaciones. En este caso, el grupo desarrollador de la guía decidió no adaptar la evidencia de las referencias identificadas, sino proceder a desarrollar una nueva guía de práctica clínica.

Posteriormente, se procedió a la revisión bibliográfica sobre los aspectos clínicos incluidos dentro de la guía, acorde con los lineamientos sugeridos por la guía metodológica del Ministerio de Salud y Protección Social ${ }^{18,19}$. Se buscaron revisiones sistemáticas y metaanálisis para las preguntas de la guía; las bases de datos seleccionadas para la búsqueda de evidencia fueron Medline (vía Pubmed y Ovid), Embase y Central (vía Ovid). La calidad de dichas revisiones fue evaluada por medio del instrumento AMSTAR. Para algunas revisiones sistemáticas evaluadas, fue necesario actualizar la 'evidencia' con búsqueda de estudios primarios recientes. Cuando no se encontraron revisiones sistemáticas, se procedió a buscar artículos originales, comenzando por ensayos clínicos, siguiendo por estudios de cohortes, de casos y controles y estudios descriptivos. 
Para la escogencia de los artículos, dos miembros del grupo desarrollador de la guía seleccionaron los títulos y resúmenes resultantes de la búsqueda sistemática de la literatura científica. Después de esta selección, se obtuvieron y revisaron los textos completos de los artículos seleccionados. Cualquier discrepancia entre evaluadores fue resuelta por consenso. Los resultados de la búsqueda definitiva fueron almacenados en el programa de manejo de referencias Endnote $\mathrm{X}_{5}{ }^{\mathrm{TM}}$. Asimismo, para la evaluación del riesgo de sesgo asociado a dichos estudios, se emplearon las escalas de evaluación sugeridas por el Scottish International Guidelines Network (SIGN) para los temas de estudios de intervenciones y observacionales, así como el QUADAS-II para los temas de estudios diagnósticos. Los resultados de esta revisión fueron consignados en tablas de evidencia elaboradas por medio del software GRADEprofiler, versión 3.6, que resumieron los datos de la evidencia valorada. Dichas tablas incluyeron información referente a: datos de identificación del es- tudio evaluado, diseño, población participante, resultados (incluyendo medidas de efecto, diagnósticas o frecuencias según el caso), conclusiones, nivel de evidencia y comentarios si hubiese lugar.

Para formular las recomendaciones, se tomaron como base las tablas de evidencia, junto con el material bibliográfico consultado y la experiencia clínica de los miembros del grupo desarrollador de la guía. Para cada pregunta con 'evidencia' disponible, se llegó a un consenso informal en el que participaron expertos clínicos y metodológicos, y los representantes de los pacientes en el grupo desarrollador de la guía. Para la generación de recomendaciones se utilizó la metodología del GRADE Working Group, la cual incluyó información referente al volumen y la calidad de la 'evidencia' identificada, al balance daño-beneficio de la intervención evaluada, a la necesidad de recursos y costos, y a las preferencias de los pacientes. Además de incluir recomendaciones clínicas basadas en la evidencia, el grupo desarrollador de la guía

\section{Niveles DE 'EVIdenCIA' - CALIDAD DE LA 'EVIDENCIA' GRADE}

\begin{tabular}{ll}
\hline \multicolumn{1}{c}{ JUICIO } & \multicolumn{1}{c}{ CARACTERÍSTICAS } \\
Alta & Es muy poco probable que nuevos estudios cambien la confianza que se tiene en el resultado estimado. \\
Moderada & $\begin{array}{l}\text { Es probable que nuevos estudios tengan un impacto importante en la confianza que se tiene en el } \\
\text { resultado estimado y que estos puedan modificar el resultado. }\end{array}$ \\
Baja & $\begin{array}{l}\text { Es muy probable que nuevos estudios tengan un impacto importante en la confianza que se tiene en el } \\
\text { resultado estimado y que estos puedan modificar el resultado. }\end{array}$ \\
Muy baja & Cualquier resultado estimado es muy incierto. \\
\hline
\end{tabular}

\section{FUERZA DE LA RECOMENDACIÓN GRADE}

\begin{tabular}{ll}
\hline FUERZA DE LA RECOMENDACIÓN & \multicolumn{1}{c}{ SIGNIFICADO } \\
Fuerte, a favor & $\begin{array}{l}\text { Las consecuencias deseables claramente sobrepasan las consecuencias indeseables. } \\
\text { SE RECOMIENDA EMPLEAR LA INTERVENCION EVALUADA. }\end{array}$ \\
Lébil, a favor & $\begin{array}{l}\text { Las consecuencias deseables probablemente sobrepasan las consecuencias indeseables. } \\
\text { SE SUGIERE EMPLEAR LA INTERVENCION EVALUADA. }\end{array}$ \\
L Débil, en contra & $\begin{array}{l}\text { Las consecuencias indeseables probablemente sobrepasan las consecuencias deseables. } \\
\text { SE SUGIERE NO EMPLEAR LA INTERVENCION EVALUADA. }\end{array}$ \\
Luerte, en contra & $\begin{array}{l}\text { Las consecuencias indeseables claramente sobrepasan las consecuencias deseables. } \\
\text { SE RECOMIENDA NO EMPLEAR LA INTERVENCIÓN EVALUADA. }\end{array}$ \\
Punto de buena & $\begin{array}{l}\text { Recomendación considerada como incuestionable o irrebatible ya que sus beneficios en } \\
\text { la práctica clínica son claros. }\end{array}$ \\
\hline
\end{tabular}

TABLA 1. Niveles de ‘evidencia’ y fuerza de la recomendación según la metodología GRADE. 
incluyó puntos de buena práctica clínica para reforzar las conductas positivas en el manejo de los pacientes objeto de la guía, cuyos efectos benéficos no se cuestionan y no conllevan riesgos asociados a su administración. Cuando no se encontró 'evidencia' para sustentar las recomendaciones o en temas críticos para la práctica clínica, se optó por el uso de métodos formales de consenso de expertos para generar las recomendaciones. En este caso, se usó el método Delphi modificado (método de apropiación RAND/UCLA). Los niveles de evidencia y fuerza de las recomendaciones, fueron graduadas por medio de la metodología GRADE (TABLA 1).

El grupo desarrollador de la guía incorporó la perspectiva de los pacientes mediante diferentes estrategias a lo largo del proceso de desarrollo de la guía de práctica clínica. Se incluyeron hombres y mujeres mayores de edad, con diagnóstico confirmado de cáncer de piel no melanoma: queratosis actínica, cáncer escamocelular o cáncer basocelular. Las etapas o momentos para la inclusión de dicha perspectiva fueron: identificación de los temas de mayor relevancia que debían incluirse en la guía de práctica clínica según la experiencia de los sujetos que han padecido cáncer de piel no melanoma, divulgación y discusión con los pacientes sobre las recomendaciones emanadas y validación de sus contenidos para los pacientes. Por último, se vincularon los diferentes grupos de interés en diferentes fases de la guía mediante mecanismos directos o indirectos (representaciones de agremiaciones, laboratoratorios y sociedades científicas, entre otros).

\section{1. ¿Cuál es la definición del carcinoma escamocelular?}

El carcinoma escamocelular cutáneo es una neoplasia maligna derivada de los queratinocitos suprabasales de la epidermis. Cuando se localiza únicamente en la epidermis o en los anexos por encima de la membrana basal, se denomina carcinoma escamocelular in situ. Cuando compromete la dermis y los tejidos subyacentes, se trata de un carcinoma escamocelular invasor $^{21}$. A partir de esta invasión a la dermis, el tumor puede diseminarse a distancia y, en este caso, se trata de un carcinoma escamocelular metastásico. La gran mayoría de casos son consecuencia de la radiación ultravioleta y, por lo tanto, se localizan en áreas de exposición solar crónica, como la cabeza, el cuello, y el dorso de las manos. Cuando se desarrollan sobre cicatrices antiguas (quemaduras o trauma) o sobre dermatosis crónicas de diversa naturaleza, estos carcinomas se conocen bajo el epónimo de úlceras de Marjolin ${ }^{22}$. Si los tumores surgen en áreas cubiertas del sol y no están relacionados con ningún proceso cicatricial, se denominan carcinomas escamocelulares de novo.

\section{2. ¿Cuáles son los factores de riesgo identificados para la aparición del carcinoma escamocelular?}

Los factores de riesgo para el desarrollo del carcinoma escamocelular cutáneo son multifactoriales, e incluyen factores de riesgo ambiental y constitucional. El principal factor de riesgo ambiental para el desarrollo de carcinoma escamocelular es la exposición crónica y temprana a la radiación ultravioleta del $\mathrm{sol}^{23}$. En varios estudios se ha encontrado una relación entre la incidencia del cáncer de piel no melanoma y la latitud. Según Johnson, et al., la incidencia del cáncer de piel no melanoma se duplica con cada 8 a 10 grados de disminución en la latitud geográfica, estimándose que las tasas más altas deberían presentarse la zona ecuatorial $^{24}$. Esta asociación también fue citada por Armstrong quien, basado en los datos de incidencia del trabajo de Scotto, et al., ${ }^{25}$, encontró una tendencia lineal en el aumento en la incidencia de cáncer de piel relacionada con la disminución en la latitud ${ }^{26}$. En el caso del carcinoma escamocelular, en tres estudios de casos y controles llevados a cabo en Europa, Australia y Estados Unidos ${ }^{27-29}$, se destaca la elevada sensibilidad a la radiación ultravioleta como un factor de riesgo que se debe tener en cuenta, así como en un estudio colombiano con 332 participantes ${ }^{30}$.

Además de la radiación ultravioleta del sol, otras fuentes se han implicado en la génesis del carcinoma escamocelular, como las cámaras de bronceo y los tratamientos médicos con PUVA (psoraleno más radiación ultravioleta A). Además de la intensidad y el tiempo de exposición a la radiación ultravioleta, rasgos constitucionales como el fenotipo y el grado de sensibilidad cutánea a dicha radiación (fototipo), son factores de riesgo para desarrollar la enfermedad ${ }^{31,32}$. Los individuos de piel clara, de ojos claros, de pelo rubio o pelirrojo y que poseen piel de fototipo I y II (quemaduras solares frecuentes y poca capacidad de bronceo), son el grupo con mayor riesgo ${ }^{27}$.

Entre otros factores ambientales de riesgo para la génesis del carcinoma escamocelular, se destacan la exposición ocupacional a hidrocarburos aromáticos poli- 


\section{"LOS FACTORES DE RIESGO PARA EL DESARROLLO DEL CARCINOMA ESCAMOCELULAR CUTÁNEO SON MULTIFACTORIALES, E INCLUYEN FACTORES DE RIESGO AMBIENTAL Y CONSTITUCIONAL"}

cíclicos, como el alquitrán y los aceites minerales ${ }^{33}$. Hay que resaltar que la mejora en las medidas de protección en los obreros, ha contribuido a la disminución de la incidencia de este tipo de carcinoma escamocelular. Otro carcinógeno químico importante en el desarrollo de este carcinoma es el arsénico, que puede encontrarse en pesticidas, algunos preparados medicinales o en ciertas fuentes de agua. Las personas expuestas al arsénico desarrollan carcinoma escamocelular o algunos otros tumores, como los de pulmón, sistema urogenital o sistema digestivo ${ }^{33}$.

El tabaco también es un factor de riesgo para el desarrollo del carcinoma escamocelular. En efecto, los fumadores activos presentan un riesgo relativo de 2,3 en relación con los no fumadores (IC ${ }_{95 \%}$ 1,5-36) 34 $^{34}$ En un estudio de casos y controles en población colombiana, se encontró que el riesgo de carcinoma escamocelular en fumadores de más de 10 cigarrillos diarios, era mayor al del grupo de no fumadores $\left(\mathrm{OR}=2,96 ; \mathrm{IC}_{95 \%} 1,3-6,5\right)^{30}$.

En las últimas décadas, el aumento de los pacientes inmunosuprimidos ha contribuido a una mayor incidencia del carcinoma escamocelular ${ }^{35}$. En efecto, esta población presenta unas tasas muy altas de carcinoma escamocelular con respecto a la población general. La inmunosupresión puede ser primaria (sida o leucemia linfoide crónica) o secundaria (por trasplante de órganos o medicación inmunosupresora para el tratamiento de diversas enfermedades $)^{36}$. En el caso de los trasplantes, el riesgo aumenta con la intensidad y la duración de la inmunosupresión. Se ha observado un mayor riesgo en los trasplantes de corazón y un menor riesgo en los de hígado. Los pacientes con mayor daño solar y con más queratosis actínicas, son los que más presentan carcinoma escamocelular ${ }^{35}$.

Un grupo importante de carcinomas escamocelulares, especialmente en Colombia, se desarrolla sobre cicatrices antiguas por quemaduras o trauma y sobre dermatosis crónicas de diversa etiología. Entre las dermatosis inflamatorias, se destacan las úlceras de miembros inferiores de origen vascular, el lupus cutáneo discoide, el liquen escleroso y atrófico, el liquen plano erosivo, la hidradenitis supurativa y los linfedemas ${ }^{37,38}$. Entre las infecciones crónicas, son de anotar las osteomielitis, las infecciones fúngicas tropicales como la cromoblastomicosis, el lupus vulgar, el linfogranuloma venéreo y el granuloma inguinal. Finalmente, algunos síndromes hereditarios, como el xeroderma pigmentoso, la epidermólisis ampollosa distrófica, la disqueratosis congénita, el albinismo y la epidermodisplasia verruciforme, entre otros, se han asociado con una mayor incidencia de esta enfermedad ${ }^{1}$.

\section{3. ¿Cuáles son las características clínicas (signos y síntomas) del carcinoma escamocelular?}

Los carcinomas escamocelulares pueden desarrollarse en la piel o en las mucosas (oral, genital y anal). Los carcinomas escamocelulares cutáneos pueden ser in situ, como la enfermedad de Bowen o carcinomas escamocelulares invasores. Entre los carcinomas de las mucosas, hay que destacar el carcinoma escamocelular del labio que, por su etiología (exposición solar crónica) y comportamiento, se asemeja más a los carcinomas cutáneos que a los carcinomas de las mucosas que son usualmente más agresivos ${ }^{39}$. La localización anatómica juega un papel importante en el comportamiento tumoral y es la base de las clasificaciones clínicas.

\section{ENFERMEDAD DE BOWEN}

Este carcinoma escamocelular in situ afecta hombres y mujeres usualmente mayores de 60 años ${ }^{40}$. Puede comprometer cualquier parte de la piel, pero es más frecuente en las áreas expuestas al sol. Se presenta típicamente como una placa de bordes definidos, escamosa, de color piel o eritematosa, y de crecimiento lento y progresivo ${ }^{41}$. Usualmente es asintomática y puede llegar a medir varios centímetros. Se han descrito variantes verrugosas, hiperqueratósicas y pig- 
mentadas ${ }^{42,43}$. Cuando compromete los pliegues, no presenta descamación y es fácil confundirla con enfermedades fúngicas. También, puede presentarse en la región ungular y simular una verruga viral benigna o un absceso periungular. En la uña, puede producir cambios de coloración, onicólisis o su pérdida ${ }^{44}$.

\section{CARCINOMA ESCAMOCELULAR DE ÁREAS EXPUESTAS AL SOL}

En la gran mayoría de casos, estos tumores surgen sobre queratosis actínicas en áreas de fotodaño crónico. Se presentan inicialmente como pápulas o placas queratósicas de color piel o eritematosas. También, pueden producir úlceras o cuernos cutáneos. Posteriormente, se pueden desarrollar nódulos o tumores ulcerados que infiltran y se fijan a los planos profundos.

\section{CARCINOMA ESCAMOCELULAR DESARROLLADO SOBRE CICATRICES (ÚLCERAS DE MARJOLIN)}

Estos carcinomas se desarrollan sobre cicatrices o úlceras que llevan décadas de evolución ${ }^{45}$. Las entidades que originan este tipo de carcinoma escamocelular, son muy variadas: quemaduras, traumas, úlceras crónicas de origen vascular, infecciones crónicas (osteomielitis, cromomicosis, granuloma inguinal, lupus vulgar o lepra, entre otros), enfermedades dermatológicas (lupus discoide, liquen plano erosivo, morfea, liquen esclerosos y atrófico, quiste pilonidal, hidradenitis supurativa, acné conglobata, enfermedad de Hailey-Hailey, foliculitis disecante del cuero cabelludo, necrobiosis lipoídica, epidermólisis ampollosa distrófica). Debe sospecharse la neoplasia maligna ante la induración y la aparición de un nódulo en la cicatriz o la úlcera.

\section{CARCINOMA ESCAMOCELULAR DE NOVO}

Aparece en áreas cubiertas y, por definición, en la piel sana. Se presenta como un nódulo o un tumor de crecimiento usualmente rápido.

\section{CARCINOMA ESCAMOCELULAR DEL LABIO}

Este carcinoma se desarrolla usualmente sobre una queilitis actínica, que es el equivalente de la queratosis actínica, en la semimucosa del labio. Se presenta como una placa queratósica persistente, un área indurada, una costra o una úlcera que puede evolucionar a un nódulo. La localización típica es el labio inferior, pues es el labio que está más expuesto al sol.

\section{CARCINOMA ESCAMOCELULAR VERRUCOSO}

Es una variante rara de carcinoma escamocelular que puede afectar la piel y las mucosas ${ }^{46}$. Clínicamente, se caracteriza por ser un tumor de crecimiento lento, exofítico, con la apariencia de una coliflor y cuyo principal diagnóstico diferencial son las verrugas virales. Se distinguen cuatro tipos. El tipo I comprende los tumores desarrollados en la mucosa intraoral, que son conocidos también como papilomatosis oral florida. El tipo II son tumores localizados en la mucosa genital y perianal, también conocidos como tumores de BushkeLowenstein. El tipo III es un tumor que se localiza en las plantas, caracterizado por su mal olor y que se conoce con el nombre de epitelioma cuniculatum. Finalmente, el tipo IV comprende los tumores localizados en otras áreas del cuerpo.

\section{QUERATOACANTOMA}

Es una forma particular de carcinoma escamocelular cutáneo, pues se trata de un tumor que presenta remisión espontánea ${ }^{47}$. Se ha especulado mucho sobre su naturaleza pero, en la actualidad, la mayoría de los autores opta por incluirlo en el capítulo de los carcinomas escamocelulares y no en el de los tumores benignos. La gran mayoría de los pacientes son adultos mayores y los tumores se presentan en áreas de exposición solar crónica. Se han descrito tres estados evolutivos. Las lesiones en el estado proliferativo crecen rápidamente hasta alcanzar un tamaño de uno a dos centímetros. En este estado, se trata de pápulas y nódulos de color piel. En el siguiente estado, el de madurez, el tumor presenta un tapón de queratina central muy característico. Si se retira, se observa en el fondo una úlcera que se asemeja al cráter de un volcán. En el estado involutivo, se observa un nódulo necrótico que puede llevar a la formación de una cicatriz.

\section{4. ¿Cuáles son las características histopatológicas del carcinoma escamocelular?}

Para el reporte de histopatología, se recomienda seguir los delineamientos del College of American Pathologists del $2013^{48}$. Además de la identificación precisa del paciente, y las fechas de toma y de reporte de la patología, deben figurar los siguientes elementos: tipo de procedimiento de toma de la biopsia, sitio anatómico del tumor, tamaño en centímetros, subtipo histológico, grado de diferenciación tumoral, grosor tumoral en mi- 
límetros, grado de invasión anatómica, presencia de invasión linfovascular, presencia de invasión perineural y márgenes quirúrgicos de la pieza. Entre los diferentes subtipos histológicos, el patólogo puede señalar los siguientes: acantolítico, fusocelular, verrugoso, pseudovascular, adenoescamoso, carcinoma escamocelular no especificado y otras variantes ${ }^{48}$.

El grado de diferenciación tumoral se clasifica en cuatro grupos. El grado 1 es un tumor bien diferenciado caracterizado por una producción abundante de queratina, con puentes intercelulares evidentes, atipia mínima y mitosis principalmente basales. Para otros patólogos, el grado 1 corresponde a tumores con diferenciación mayor del $75 \%$. El grado 2 es un tumor moderadamente diferenciado, con un grado de queratinización menor del anterior, mayor atipia celular y mitosis. También, se pueden definir como tumores con un grado de diferenciación entre el 50 y el 75 \%. El grado 3 es un tumor pobremente diferenciado, en el cual es difícil de establecer la diferenciación escamosa. También, se pueden definir como tumores con un grado de diferenciación entre el 25 y el $50 \%$. El grado 4 es un tumor indiferenciado o en el cual el grado de diferenciación es menor del $25 \% 0^{48}$. Para reportar el grosor tumoral, se necesita un lente ocular micrométrico calibrado. El punto superior corresponde a la capa granulosa o a la base de la úlcera en los tumores ulcerados y el punto inferior corresponde a la parte más profunda de la invasión tumoral. Si la parte profunda de la biopsia se encuentra comprometida por el tumor, se debe informar el grosor en milímetros ${ }^{48}$.

El grado de invasión se califica de manera análoga a como se hace en la clasificación del Clark. El nivel I corresponde a los tumores in situ; el nivel II, a los que comprometen la dermis papilar sin ocuparla completamente; el nivel III, a los que comprometen toda la dermis papilar; el nivel IV, a los que comprometen la dermis reticular hasta el límite con la grasa, y, el nivel V, a los que comprometen la grasa ${ }^{48}$. Para la invasión linfovascular o la invasión perineural, el patólogo debe escoger entre los siguientes distractores: no identificada, presente o indeterminada ${ }^{48}$.

\section{5. ¿Cuáles son las estrategias más efectivas para la prevención primaria y secundaria del carcinoma escamocelular?}

(Para una síntesis de las recomendaciones sobre estrategias de prevención, ver la TABLA 2).

En un ensayo clínico de asignación aleatoria llevado a cabo en estudiantes universitarias con una intervención basada en la apariencia, se observó una reducción en el riesgo de la exposición prolongada al sol por medio del bronceo, a seis meses de intervención ${ }^{49}$ (CALIDAD MUY BAJA). En un segundo ensayo clínico en voluntarios de una comunidad, el empleo de mensajes de texto para recordarles el uso del protector solar, comparado con una población a la que no se le envió el mensaje de texto, incrementó en $20 \%$ el cumplimiento de esta intervención a seis semanas de seguimiento (p<0,001). El $69 \%$ de los sujetos intervenidos manifestaron que seguirían recibiendo los mensajes, y el $89 \%$ lo recomendaría a amigos y familiares $^{50}$ (CALIDAD MODERADA).

En instituciones de educación preescolar, se implementó la estrategia 'Block the sun, not the fun', dirigida principalmente a cuidadores de los centros educativos y, secundariamente, a los padres y los niños. Esto incluyó sesiones de trabajo con los grupos, e información y paquetes de actividades para los padres. Aunque no se observaron cambios significativos en las actitudes y prácticas de protección solar de los niños por parte de los padres, se observó un cambio importante en el conocimiento y las actitudes de los directores de los centros, y los padres manifestaron satisfacción con las actividades realizadas en el colegio con el fin de reducir la exposición ${ }^{51}$ (CALIDAD MODERADA).

En otro estudio en entorno escolar, se compararon clases de colegios asignados aleatoriamente para ser intervenidos con el programa 'Living with the sun', el cual está diseñado para que los niños mejoren sus conocimientos sobre la exposición al sol, y modificar positivamente sus comportamientos y actitudes hacia la protección solar. Al cabo de un año, aunque ambos grupos mostaron haber mejorado sus conocimientos sobre la protección social, el grupo intervenido reportó mayor uso de protector solar, sombrero y sombrilla en la playa ${ }^{52}$ (CALIDAD MODERADA).

En 2002, se implementó una estrategia para incrementar la adopción de la política emitida por los Centers for Disease Control and Prevention (CDC) para reducir la exposición solar de los estudiantes en los colegios, por parte de instituciones educativas públicas distritales en Colorado (Estados Unidos). La intervención implicó suministrar información sobre la política, las herramientas y la asistencia técnica, así como la conformación de equipos de apoyo y reuniones con los administradores. Aunque no se detectaron diferencias en la cantidad de colegios que adoptaron las políticas, en comparación con los colegios no intervenidos, los intervenidos implementaron de forma significativa estrategias más fuertes para la prevención de la exposición, como provisión de sombra en el exterior, educación 


\section{ESTRATEGIAS DE PREVENCIÓN}

Se recomienda, para la población general, promover medidas que reduzcan la exposición a la radiación ultravioleta y disminuyan el riesgo de desarrollar queratosis actínica, las cuales incluyen:

- Uso de medidas de barrera física (sombrero, ropa adecuada).

FUERTE,

- Evitar la exposición en horas de mayor radiación ultravioleta.

- Buscar la sombra al practicar actividades al aire libre.

- Uso de barreras químicas (protección solar).

\section{PREVENCIÓN PRIMARIA: USO DE MEDIDAS DE PROTECCIÓN FISICA}

Para la población general, se recomienda promover medidas que eviten la exposición a la radiación ultravioleta, especialmente entre las 9 a.m. y las 4 p.m.

Para la población general, se recomienda buscar la sombra al practicar actividades y en desplazamientos al aire libre.

FUERTE, A FAVOR

FUERTE, A FAVOR

Para la población general, se recomienda usar vestimenta apropiada: sombrero de ala ancha y ropa de

FUERTE, manga y bota larga, que impidan el paso de la radiación ultravioleta.

A FAVOR

PREVENCIÓN PRIMARIA: USO DE MEDIDAS TÓPICAS DE PROTECCIÓN

Se recomienda el uso de barreras químicas (protector solar) en conjunto con otras medidas de protección física, para la prevención de la queratosis actínica.

FUERTE, A FAVOR

Se recomienda que el protector solar sea de amplio espectro (rayos ultravioleta A y B), con un factor de

CONSENSO protección solar de mínimo 30.

\section{PREVENCIÓN PRIMARIA: USO DE MEDIDAS SISTÉMICAS DE PROTECCIÓN}

No se recomienda, para la población general, el uso de betacaroteno para la prevención de queratosis actínica.

No se sugiere el uso de Polypodium leucotomos ni de extracto de corteza de pino marítimo francés, para la DÉBIL prevención de la queratosis actínica en la población general.

EN CONTRA

FUERTE,

No se recomienda, para la población general, el uso de AINE para la prevención de la queratosis actínica.

EN CONTRA

\section{PREVENCIÓN PRIMARIA: USO DE OTRAS MEDIDAS}

No se sugiere prescribir dietas específicas (mayor consumo de vegetales o menor consumo de grasas) a la población general, como parte de las estrategias preventivas de la queratosis actínica.

DÉBIL

EN CONTRA

No se recomienda el uso de cámaras de bronceo, debido al aumento del riesgo de cáncer de piel en la

FUERTE, población general.

EN CONTRA

\section{PREVENCIÓN PRIMARIA: USO DE MEDIDAS DE SALUD PÚBLICA}

Se recomienda la realización de campañas educativas integrales (las cuales incluyen publicidad, cartillas educativas y educación dirigida a la población general) para la prevención de la queratosis actínica, las cuales FUERTE proporcionen conocimientos referentes a los riesgos de la exposición a la radiación ultravioleta y promuevan la modificación de dichas conductas de riesgo.

Se recomienda que las campañas educativas integrales para la prevención de queratosis actínica (las cuales incluyen publicidad, cartillas educativas y educación dirigida a la población general), sean reforzadas periódicamente para mantener la observancia de las intervenciones preventivas.

FUERTE

A FAVOR

$$
\text { PREVENCIÓN SECUNDARIA }
$$

Se recomienda el uso de medidas de protección física (reducir la exposición solar entre las 9 a.m. y las 4 p.m., buscar la sombra al practicar actividades y desplazamientos al aire libre, usar vestimenta apropiada: sombrero de ala ancha y ropa de manga y bota larga) y química (protector solar), para la prevención FUERTE secundaria de la queratosis actínica.

Se recomienda que el protector solar sea de amplio espectro (rayos ultravioleta A y B), con un factor de protección solar de mínimo 30.

No se recomienda el uso de betacaroteno para la prevención secundaria del carcinoma escamocelular. 
sobre protección solar a los estudiantes y divulgación a los padres $^{53}$ (CALIDAD MUY BAJA).

El envío de notificaciones modificadas más la administración de recursos de protección de la piel a padres e hijos entre los cinco a nueve años, durante tres años, mostró un impacto positivo en el empleo de medidas de protección de barrera, el cual fue estadísticamente significativo. Sin embargo, la relación no fue clara con resultados de exposición al sol (bronceado, aparición de nevus, etc.), así como tampoco en mediadores cognitivos, como atención a los factores de riesgo y conocimiento sobre protección de barrera o de factores de riesgo $^{54}$ (CALIDAD MODERADA).

Por otra parte, en playas públicas de Massachusetts se invitó a mujeres a emplear estrategias de bronceo que no emplearan el sol, con la instrucción sobre el uso de autobronceadores y enseñanza sobre los riesgos de la exposición, mientras que un grupo de mujeres control completaron una encuesta relacionada. A dos meses de esta intervención, se reportó una disminución significativa de la exposición al sol, uso más frecuente de ropa protectora y menos quemaduras solares en las mujeres intervenidas, pero, a un año, no se observaron diferencias en las quemaduras solares, aunque sí en el reporte de empleo de estrategias de prevención ${ }^{55}$ (CALIDAD MUY BAJA).

\section{MEdIDAS DE PROTECCIÓN FÍSICA}

En el ensayo clínico "Sun Protection of Florida's Children", se promovió el uso de sombrero dentro y fuera del colegio en estudiantes de cuarto grado, por medio de la provisión de los sombreros y la inclusión de sesiones de clase sobre su uso y normas de uso. En los colegios control, su uso se mantuvo cercano al o \%, mientras que en los colegios intervenidos, alcanzó el 30 y $40 \%$ de uso en el colegio, en otoño y primavera, respectivamente. El autorreporte de uso de sombrero fuera del colegio y los niveles de pigmentación entre los dos grupos, no tuvieron cambios significativos entre las dos poblaciones ${ }^{56}$ (CALIDAD MODERADA).

Por otra parte, en dos estudios se evaluó la relación entre el uso de cámaras bronceadoras y el riesgo de carcinoma escamocelular y basocelular. Zhang, et al. ${ }^{57}$, emplearon los datos de una cohorte de 73.494 enfermeras observadas de forma prospectiva durante 20 años, entre 1989 y 2009. En estas pacientes se describió el uso de cámaras bronceadoras $\mathrm{y}$, para aquellas que reportaron carcinoma basocelular o escamocelular, se corroboraron los datos con las historias clínicas. La incidencia de carcinoma escamocelular no mostró asociación con el uso de cámaras bronceadoras, al menos, cuatro veces al año durante el bachillerato o la universidad, aunque sí se asoció con su uso, al menos, cuatro veces al año entre los 25 y 35 años (RR=1,19; $\left.I_{95 \%} 0,84-1,67\right)$ y (RR 1,43; IC $\left.{ }_{95 \%} 1,15-1,76\right)$, respectivamente). En este estudio se encontró una relación dependiente de la dosis entre el número de veces que la paciente reportó exponerse al año y el riesgo de carcinoma escamocelular o basocelular. Por su parte, Karagas, et al..$^{8}$, compararon 603 sujetos con carcinoma basocelular y 293 con carcinoma escamocelular, recientemente diagnosticados, con 540 sujetos control, para determinar el antecedente de exposición a cámaras de bronceo. Se encontró una asociación positiva significativa para el carcinoma basocelular ( $\mathrm{OR}=1,5$ IC $\left._{95 \%} 1,1-2,1\right)$ y el escamocelular $\left(\mathrm{OR}=2,5 ; \mathrm{IC}_{95 \%}\right.$ 1,7-3,8) (CALIDAD MODERADA).

\section{MEDIDAS DE PROTECCIÓN TÓPICA}

En un ensayo clínico publicado en 1999, se asignaron aleatoriamente sujetos entre 18 y 24 años para recibir protector solar con SPF10 o SPF30, sin recomendaciones adicionales sobre otras acciones de protección solar. A pesar de que el factor de protección solar del bloqueador administrado estaba enmascarada, los sujetos con mayor factor de protección solar tenían mayor exposición al sol y actividades en el exterior sin protección adicional al protector, aunque no se detectaron diferencias entre el número de quemaduras o el enrojecimiento ${ }^{59}$ (CALIDAD ALTA). En otro estudio, en el cual los sujetos se asignaron aleatoriamente para usar protector solar diariamente o a discreción, los participantes fueron observados por seis años adicionales para valorar la persistencia en el uso del protector. Se observó que los sujetos asignados al grupo de aplicación diaria del protector, fueron más proclives a mantener este hábito, en comparación con el grupo de aplicación a discreción ${ }^{60}$ (CALIDAD MODERADA).

El empleo de un protector solar en pacientes sometidos a radiación solar simulada, se asoció con una reducción significativa en el número de estratos córneos $(19,8$ Vs.15,0) y granulosos (1,8 Vs. 1,1), y formación de melanina $(3,2$ Vs. 1,4), a las seis semanas de seguimiento, en comparación con los pacientes sometidos a radiación sin bloqueador. Además, generó un mayor grosor de epidermis viable $(85,2$ Vs. 90,0). Este estudio concluye que el factor de protección solar determinado con base en una reacción de eritema agudo no predice el grado de protección contra el daño solar acumulativo ${ }^{61}$ (CALIDAD MUY BAJA).

Por otra parte, se llevó a cabo un ensayo clínico factorial para evaluar si el uso de protector solar con SPF15 más suplemento de betacaroteno (30 mg/día), con seguimiento a 4,5 años, disminuía la incidencia de cáncer basocelular o escamocelular. No se detectaron diferencias entre el grupo asignado aleatoriamente al uso diario 
de protector solar y aquel sin protector solar, así: carcinoma basocelular: 2.588 Vs. 2.509 por $100.000(\mathrm{RR}=1,03$; $\mathrm{IC}_{95 \%}$ 0,73-1,46); y carcinoma escamocelular: 876 Vs. 996 por $100.000\left(\mathrm{RR}=0,88 ; \mathrm{IC}_{95 \%} 0,50-1,56\right)$. Sin embargo, se observaron $5 \%$ de eventos adversos relacionados con su uso diario, mientras que en el grupo control no se observaron eventos adversos ${ }^{62}$ (CALIDAD MODERADA).

Finalmente, se realizó el ensayo 'Veterans Affairs Tropical Tretinoin Chemoprevention Trial', con el fin de evaluar el efecto de la tretinoína para la prevención del cáncer de piel no melanoma. Al comparar la administración de tretinoína tópica al o,1 \% Vs. placebo, durante 1,5 a 5,5 años, no se encontraron diferencias significativas para el carcinoma basocelular $(p=0,3)$ ni el escamocelular $(\mathrm{p}=0,4)$. Sin embargo, se observó una mayor tasa de eventos adversos en el grupo con tretinoína $^{63}$ (CALIDAD MODERADA).

\section{MedidAs de PROTECCIÓN SISTÉMICA}

En un estudio similar en mujeres posmenopáusicas entre los 50 y los 79 años de edad, se hizo asignación aleatoria para recibir una dieta baja en grasa Vs. controles sin intervención en la dieta, con seguimiento cada seis meses. Con un promedio de seguimiento de 8,1 años, la dieta baja en grasa no disminuyó la incidencia de cáncer de piel no melanoma $\left(\mathrm{HR}=0,98 ; \mathrm{IC}_{95 \%} 0,92-1,04\right)^{64}$ (CALIDAD MODERADA).

En 1999, se realizó un ensayo clínico factorial para evaluar si el uso de protector solar con SPF15 más suplemento de betacaroteno ( $30 \mathrm{mg} /$ día), con seguimiento a 4,5 años, disminuye la incidencia de cáncer basocelular o escamocelular. No se detectaron diferencias significativas entre el grupo que recibió betacaroteno Vs. el grupo con placebo: carcinoma basocelular, 3.954 Vs. 3.806 por 100.000 ( $R R=1,04 ; I_{95 \%}$ 0,73-1,27), y carcinoma escamocelular, 1.508 Vs. 1.146 por $100.000\left(\mathrm{RR}=1,35\right.$; $_{95 \%} 0,84^{-}$ 2,19) $)^{62}$ (CALIDAD MODERADA). En general, la protección contra carcinoma basocelular con el uso de betacaroteno, no mostró significancia estadística para el carcinoma basocelular ( $\mathrm{HR}=1,04$; $\mathrm{IC}_{95 \%}$ o,73-1,27) ni el escamocelular $\left(\mathrm{HR}=1,35 ; \mathrm{IC}_{95 \%} 0,84-2,19\right)$, ni tampoco en relación con eventos adversos ( $\left.R R=0,5 ; I_{95 \%} 0,3-1,1\right)^{62}$ (CALIDAD MODERADA).

Por otra parte, se llevó a cabo un estudio de casos y controles sobre carcinoma escamocelular, carcinoma basocelular y melanoma incidentes entre 1991 y 2009 en Dinamarca, y se compararon con aproximadamente 10 poblaciones control, ajustando por importantes variables confusoras. Se evaluó el antecedente de consumo de aspirina y otros AINE no selectivos, o inhibi- dores COX-2 selectivos. El antecedente de más de dos prescripciones Vs. dos o menos, se asoció con menor riesgo de carcinoma escamocelular $\left(\mathrm{RR}=0,85\right.$; $\mathrm{IC}_{95 \%}$ 0,76-0,94) y de melanoma ( $\left.R R=0,87 ; \mathrm{IC}_{95 \%} 0,80-0,95\right)$, especialmente con el uso por más de siete años. No se asoció con carcinoma basocelular $\left(\mathrm{RR}=0,97 \mathrm{IC}_{95 \%}\right.$ 0,93$1,01)$, aunque en sitios diferentes a cabeza y cuello, a largo plazo, sí se encontró una asociación protectora $\left(\mathrm{RR}=0,85 ; \mathrm{IC}_{95 \%} 0,76-0,95\right)$, así como con su uso intenso $\left(\mathrm{RR}=0,79 ; \mathrm{IC}_{95 \%} 0,69-0,91\right)^{69}$.

En un segundo estudio de casos y controles, se compararon 415 pacientes con carcinoma escamocelular diagnosticados en 2004 Vs. 415 sujetos pareados por edad, sexo y etnia, sin historia de cáncer. Se evaluó el antecedente de consumo de AINE en los 10 años previos; no hubo asociación entre el carcinoma escamocelular y el uso de AINE (OR=1,32; $\mathrm{IC}_{95 \%}$ O,92-1,89), de aspirina (OR=1,38; $\mathrm{IC}_{95 \%} \mathrm{O}, 96$ 1,97), de ibuprofeno (OR=0,74; $\left.\mathrm{IC}_{95 \%} 0,46-1,19\right)$ o de AINE diferentes a la aspirina $\left(\mathrm{OR}=0,84 ; \mathrm{IC}_{95 \%} 0,56-1,26\right)$. Tampoco se detectó asociación explorando duración, dosis o interacciones entre estas variables ${ }^{70}$.

En un tercer estudio de casos y controles, llevado a cabo en 1.621 personas de Queensland (Australia) con carcinoma escamocelular, comparadas con 187 controles pareados por edad y sexo, se reportó menor frecuencia de consumo de AINE comparados con los controles que consumieron 8 veces o más a la semana, durante más de un año $\left(\mathrm{OR}=0,07 \mathrm{IC}_{95 \%} 0,01-0,71\right)$, o haber usado AINE a dosis completas dos o más veces a la semana durante más de cinco años $\left(\mathrm{OR}=0,20 ; \mathrm{IC}_{95 \%}\right.$ o,04-0,96). Además, los pacientes con carcinoma escamocelular usuarios regulares de AINE, tuvieron menos lesiones de queratosis actínica, comparados con los no usuarios $\left(\mathrm{RR}=0,52 ; \mathrm{IC}_{95 \%} 0,30-0,91\right)^{71}$. En un cuarto estudio de casos y controles se encontró que el uso de AINE, especialmente la aspirina, redujo el riesgo de carcinoma escamocelular, particularmente en aquellos sensibles a la proteína p53 $\left(\mathrm{OR}=0,29 ; \mathrm{IC}_{95 \%}\right.$ 0,11-0,79). No se encontró relación entre AINE y carcinoma escamocelular. Se observó una discreta relación protectora entre el carcinoma escamocelular o el basocelular y el acetaminofén $^{72}$ (CALIDAD MODERADA).

En una población incluida en un ensayo clínico diseñado para evaluar el efecto del retinol en la incidencia de cáncer de piel no melanoma, se evaluó el efecto del consumo de AINE en este mismo resultado. Se encontró que los AINE protegían a la población contra el carcinoma escamocelular y el basocelular: $\left(\mathrm{HR}=0,49 ; \mathrm{IC}_{95 \%} 0,28-0,87\right) \mathrm{y}$ $\left(\mathrm{HR}=0,43 ; \mathrm{IC}_{95 \%} 0,25-0,73\right)$, respectivamente. Se encontró que con AINE diferentes a la aspirina hubo mayor protección frente al carcinoma basocelular, con una duración de su consumo menor al tiempo de duración del es- 
tudio. No se detectaron diferencias en la presentación de eventos adversos ${ }^{73}$ (CALIDAD MODERADA).

Finalmente, en un estudio se encontró que el extracto de Polypodium leucotomos por vía oral producía mejoría leve en la mayor parte de los pacientes con fotodermatosis idiopática (9/25), seguida por normalización de los síntomas (7/25), sin mejoría (5/25) y clara mejoría $(4 / 25)^{74}$. Un paciente con antecedentes de colon irritable, presentó empeoramiento de los síntomas gastrointestinales. La administración oral de $7,5 \mathrm{mg} / \mathrm{kg}$ de $P$. leucotomos en nueve pacientes expuestos a radiación ultravioleta, mostró efectividad como quimioprotector de la piel contra dicha radiación a 24 horas de la intervención, al disminuir significativamente el eritema, los marcadores intermedios de daño cutáneo y la infiltración mastocítica de la piel ${ }^{75}$ (CALIDAd MUY BAJA). Asimismo, la administración del extracto de pino marítimo francés a dosis de $1,10 \mathrm{mg} / \mathrm{kg}$ al día generó una dosis mínima para eritema inducido por radiación ultravioleta de 34,62 $\mathrm{mm}^{2}$, mientras que, a $1.66 \mathrm{mg} / \mathrm{kg}$ al día, fue de $39,63 \mathrm{~mm}^{2}$. En resumen, la dosis de radiación ultravioleta necesaria para obtener una dosis de eritema mínimo se aumentó durante el suplemento con el extracto de pino marítimo francés $^{76}$ (CALIDAD MUY BAJA).

\section{OTRAS RECOMENDACIONES}

En personas con cáncer de piel no melanoma, el tratamiento con betacaroteno no reduce la aparición de

\section{HERRAMIENTAS DIAGNÓSTICAS}

Se recomienda practicar biopsia a todos los pacientes con lesiones sugestivas de carcinoma escamocelular, así como de las queratosis actínicas resistentes al tratamiento.

Se sugiere el uso de imágenes diagnósticas en el carcinoma escamocelular de alto riesgo, con el fin de evaluar la extensión local (tomografía axial con contraste, resonancia magnética o ambas) y el compromiso regional (ecografía, tomografía axial con contraste o ambas) del tumor.

TABLA 3. Herramientas diagnósticas recomendadas para evaluar las lesiones sugestivas de carcinoma escamocelular. nuevas lesiones de piel, a cinco años de tratamiento y observación ${ }^{77}$ (CALIDAD ALTA).

\section{6. ¿Cuáles son las herramientas diagnósticas recomendadas para evaluar las lesiones sugestivas de carcinoma escamocelular?}

(Para una síntesis de las recomendaciones, ver la TABLA 3).

Se encontraron dos estudios en los cuales se discuten aspectos tangenciales a la capacidad diagnóstica de la biopsia en el carcinoma escamocelular. En el primero se evaluó la presencia de carcinoma residual en una muestra de 100 pacientes con biopsias e histopatologías documentadas, de los cuales 43 casos fueron carcinomas escamocelulares $^{78}$. A todos los pacientes se les practicó una biopsia por afeitado y, después, escisión quirúrgica sin legrado (curettage) previo y con márgenes de $4 \mathrm{~mm}$. De los casos de carcinoma escamocelular, 27,9\% tuvieron residuos positivos, mientras que en las escisiones de carcinoma basocelular se encontró un porcentaje de 59,6 \% (CALIDAD MUY BAJA).

En el segundo estudio, los autores recopilaron información retrospectiva de 910 tumores de piel no melanoma (179 carcinomas escamocelulares), a los cuales se les practicó biopsia y, posteriormente, se removieron quirúrgicamente para evaluar la regresión del tumor ${ }^{79}$. De los carcinomas escamocelulares, 93 tuvieron biopsia por afeitado mientras 84 fueron sometidos a biopsia con sacabocado. La regresión del tumor se definió como la ausencia de tumor residual en la cicatriz. Los autores encontraron $52 \%$ de regresión en los casos de carcinoma escamocelular intervenidos con biopsia por afeitado, en comparación con $26 \%$ de aquellos intervenidos con biopsia con sacabocado ( $\mathrm{p}<0,05)$ (CALIDAD BAJA).

Por otra parte, Hacioglu, et al., analizaron la información de 80 lesiones de menos de $12 \mathrm{~mm}$ y sugestivas de cáncer de piel no melanoma, de 76 pacientes mayores de 18 años de una clínica ambulatoria en Turquía ${ }^{80}$. Del total de lesiones, 3,7 \% eran carcinomas escamocelulares, mientras que $30 \%$ fueron carcinomas basocelulares. En primer lugar, los pacientes fueron evaluados por el primer investigador quien hizo un diagnóstico inicial basado en la historia clínica y los hallazgos dermatológicos. Después de esta evaluación, se tomaron imágenes por medio del SIAscope $\mathrm{V}^{\circledR}$ y se practicaron biopsias de las lesiones (3 a $4 \mathrm{~mm}$ ). Las imágenes fueron revisadas por el mismo investigador y por un segundo evaluador ocho meses después de la evaluación inicial. Un tercer 


\section{CLASIFICACIÓN DEL PRONÓSTICO}

Se recomienda el uso de la clasificación TNM-2010, séptima versión del American Joint Committee on Cancer (AJCC) de los Estados Unidos para la estadificación del carcinoma escamocelular.

Para evaluar el tumor primario $(\mathrm{T})$, considere los siguientes grupos y factores de riesgo:

\section{GRUPOS DE CLASIFICACIÓN}

- TX: tumor no evaluable.

- To: sin evidencia de tumor primario.

- Tis: carcinoma in situ.

- T1: tumor menor de $2 \mathrm{~cm}$ con menos de dos factores de riesgo.

- T2: tumor de 2 o más cm, o tumor de cualquier tamaño con dos o más factores de riesgo.

- T3: tumor con invasión a maxilar, mandíbula, órbita o hueso temporal.

- T4: tumor con invasión a esqueleto axial o apendicular, o con invasión perineural de la base del cráneo.

\section{FACTORES DE RIESGO}

- Localización anatómica (oreja o labio).

- Grosor tumoral mayor de $2 \mathrm{~mm}$ (equivalente de Breslow).

- Clasificación de Clark IV o mayor.

- Invasión perineural.

- Tumor pobremente diferenciado o indiferenciado.

Se recomienda, después de la clasificación TNM, usar la clasificación de Jambusaria-Pahlajani, et al. (2013), para los pacientes con carcinoma escamocelular de piel:

- T1: sin factores de riesgo.

- T2a: presencia de un factor de riesgo.

- T2b: presencia de dos a tres factores de riesgo.

- T3: presencia de cuatro factores de riesgo.

Los factores de riesgo que se deben tener en cuenta en estos casos, son:

FUERTE,

A FAVOR

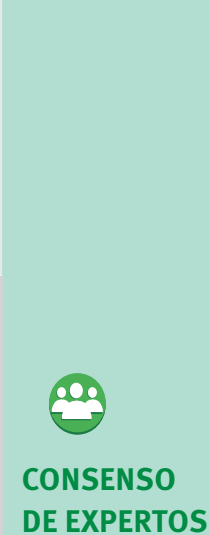

- Diámetro tumoral de 20 más cm.

- Pobre diferenciación histopatológica.

- Invasión perineural.

- Invasión más allá de la grasa subcutánea (sin incluir hueso).

Como herramienta complementaria a la clasificación TNM y a la de Jambusaria-Pahlajani, et al. (2013), se recomienda tener en cuenta otros factores pronósticos adversos del carcinoma escamocelular no incluidos en las clasificaciones antes mencionadas:

- Carcinoma escamocelular de piel de rápido crecimiento.

- Carcinoma escamocelular recurrente de piel.

- Carcinoma escamocelular de piel originado en una úlcera, cicatriz o área irradiada.

- Bordes clínicos del tumor mal definidos.

- Carcinoma escamocelular adenoide, adenoescamoso o desmoplásico.

TABLA 4. Clasificación del pronóstico de los diferentes tipos de carcinoma escamocelular.

evaluador empleó dermatoscopia sobre las imágenes, desconociendo los resultados iniciales con los otros métodos diagnósticos. Se estableció el diagnóstico histopatológico como el patrón de referencia para los casos de cáncer de piel no melanoma. En el caso del diagnóstico clínico del primer evaluador, se encontraron valores de sensibilidad de 0,79, especificidad de 0,84, valor diagnóstico positivo de o,74 y valor diagnóstico negativo de 0,87. El área bajo la curva para el diagnóstico clínico fue de o,82 unidades (CALIDAD BAJA).

Demir, et al., evaluaron el papel de la biopsia de gan- glio centinela junto con la gammagrafía linfática, en pacientes con carcinomas escamocelulares calificados como de alto riesgo ${ }^{81}$. Incluyeron 19 pacientes que fueron sometidos a linfogammagrafía preoperativamente, para establecer el número y la localización aproximada de los ganglios centinela, hallazgos discutidos con el cirujano antes de la intervención quirúrgica para la escisión completa del tumor. Los ganglios removidos fueron examinados histopatológicamente. Los autores reportaron 53 biopsias de ganglios linfáticos, 29 de los cuales eran ganglios centinela. Ninguno de los ganglios 
evaluados tenía signos de metástasis, acorde con los resultados histopatológicos. En el seguimiento de 7 a 80 meses, hubo cinco muertes no relacionadas con el carcinoma escamocelular y una recurrencia local a 31 meses después de la cirugía (CALIDAD MUY BAJA).

\section{7. ¿Cómo se recomienda clasificar el pronóstico de los diferentes tipos de carcinoma escamocelular?}

(Para una síntesis de las recomendaciones, ver la TABLA 4)

Brantsch, et al., llevaron a cabo un estudio prospectivo de cohortes sin comparación, de 653 pacientes analizados en un departamento alemán de dermatología; su objetivo consistió en buscar factores pronósticos de riesgo de recurrencia local o metástasis en pacientes con carcinoma escamocelular, usando la clasificación $\mathrm{TNM}^{82}$. Encontraron un mayor riesgo en aquellos con un tumor de más de $6 \mathrm{~mm}$ de grosor y tamaño horizontal superior a $20 \mathrm{~mm}\left(\mathrm{HR}=4,79 ; \mathrm{IC}_{95 \%} 2,22-10,36\right)$; 90 pacientes $(14 \%)$ exhibieron esta característica. Por otra parte, Clark, et al., hicieron un análisis prospectivo de 603 pacientes mediante bases de datos de dos centros hospitalarios, mientras comparaban la $7^{\mathrm{a}}$-versión de la clasificación del American Joint Committee On Cancer (AJCC) con el sistema de estadificación $\mathrm{N}_{1} \mathrm{~S}_{3}{ }_{3}^{83}$; respecto a este sistema, los autores reportaron un incremento del riesgo y disminución de la supervivencia a cinco años al comparar los casos con estadio $\mathrm{N}_{3}$ Vs. $\mathrm{N}_{1}\left(\mathrm{HR}=2,1\right.$; $\mathrm{IC}_{95 \%}$ 1,84-2,41) (CALIDAD MUY BAJA).

Más recientemente, Jambusaria, et al., propusieron un sistema de clasificación alterno complementario al de TNM adoptado por el AJCC, para intentar clasificar mejor el estadio $\mathrm{T}_{2}{ }^{84}$. Así, estudiaron mediante cohorte retrospectiva a 237 pacientes con 256 tumores, y encontraron que el mayor riesgo para una menor supervivencia era tener metástasis ganglionar $\left(\mathrm{HR}=7,2 ; \mathrm{IC}_{95 \%}\right.$ 3,1-17,1). Previamente, Andruchow, et al., condujeron un estudio retrospectivo multicéntrico de cohorte, reuniendo las historias de 322 pacientes con carcinoma escamocelular metastásico, en Australia y en Norteamérica, atendidos entre 1960 y 2003, con una mediana de tiempo de observación de dos años ${ }^{85}$; querían evaluar una propuesta de clasificación que incluyera dos estadios $\mathrm{P}$ (parótida) y $\mathrm{N}$ (neck, cuello). Respecto a la metástasis a parótida, encontraron que 50 de 149 pacientes (33,6 \%) desarrollaron estadio $\mathrm{P}_{1}$, mientras que 30 de 111 (27\%) tuvieron esta$\operatorname{dios} \mathrm{P}_{2}$ y $\mathrm{P}_{3}\left(\mathrm{RR}=1,24 ; \mathrm{IC}_{95 \%} 0,85-1,82\right)$; la supervivencia a cinco años fue de $82 \%$ en estadio $\mathrm{P}_{1}$ Vs. 69\% en estadios $\mathrm{P}_{2}$ o $\mathrm{P}_{3}(\mathrm{p}=0,02)$ (CALIDAD MUY BAJA).

Sobre la propuesta de una clasificación que incluyese $\mathrm{P}$ (parótida) y N (neck, cuello), Forest, et al., ejecutaron una revisión a manera de una cohorte retrospectiva, en la que incluyeron 250 pacientes estudiados entre $1987 \mathrm{y}$ 2007, todos con antecedentes de cirugía previa por carcinoma escamocelular y con una mediana de tiempo de seguimiento de 54 meses $^{86}$. Reportaron una menor supervivencia sin enfermedad a cinco años en los 26 (42\%) pacientes que presentaron estadio $\mathrm{N}_{3}$ (múltiples ganglios linfáticos mayores de $3 \mathrm{~cm})\left(\mathrm{HR}=5,63\right.$; $\mathrm{IC}_{95 \%} 2,2-$ 14,38) (CALIDAD MUY BAJA).

Finalmente, Breuninger, et al., compararon las clasificaciones TNM propuestas por la Unión Internacional Contra el Cáncer (UICC) y por el AJCC, para lo cual emplearon una serie de 615 casos en un único hospital ${ }^{87}$. Reportaron que 26 de 615 pacientes (4,2 \%) habían presentado metástasis, principalmente en el área de la cabeza y el cuello, con extensión a músculo, cartílago y hueso. Concluyeron que ninguna de las dos clasificaciones brindaba información con relación a este pronóstico.

Asimismo, Ch'ng, et al., evaluaron una serie de 239 casos con diagnóstico de carcinoma escamocelular metastásico en un instituto quirúrgico de cabeza y cuello, en Sydney (Australia) ${ }^{88}$; reportaron una mejor supervivencia específica para la enfermedad (DSS, disease-specific survival) si los tumores estaban bien diferenciados en el examen histopatológico ( $\mathrm{HR}=0,2$; $\mathrm{IC}_{95 \%}$ 0,1-0,8). En sus conclusiones, consideraron validado el sistema TNM propuesto por la AJCC (CALIDAD MUY BAJA).

\section{8. ¿Cuáles son las intervenciones quirúrgicas y no quirúrgicas recomendadas para el manejo del carcinoma escamocelular?}

(Para una síntesis de las recomendaciones, ver la TABLA 5)

En una revisión sistemática de estudios observacionales desarrollada por Lansbury, et al. ${ }^{89}$, se evaluó la escisión quirúrgica en 23 estudios de pacientes con carcinoma escamocelular de piel en diferentes estadios (CALIDAD MUY BAJA). En 18 estudios se evaluó la recurrencia local durante el seguimiento después de la intervención quirúrgica, con resultados de o a $15 \%$; la estimación conjunta para los estudios incluidos fue de 5,4 \% ( IC $_{95 \%} 2,5-$ 9,1; $\mathrm{I}^{2}=81 \%$ ). Los autores de la revisión reportaron que factores como la duración del seguimiento (desde menos 


\section{INTERVENCIONES QUIRÚRGICAS Y NO QUIRÚRGICAS}

Se recomienda que la elección del tratamiento más adecuado para el manejo del carcinoma

Se recomienda adoptar las siguientes definiciones para el tratamiento del carcinoma escamocelular:

- Terapias con control histológico: aquellas intervenciones que permiten el control de los márgenes por histopatología. Estas incluyen la cirugía convencional y la cirugía micrográfica de Mohs.

- Terapias sin control histológico: aquellas intervenciones que no permiten el control de los márgenes por histopatología. Incluyen técnicas destructivas (como criocirugía, electrodesecación/curettage, radioterapia, terapia fotodinámica) y tratamientos tópicos (como 5 -fluorouracilo e imiquimod).

\section{CARCINOMA ESCAMOCELULAR IN SITU - ENFERMEDAD DE BOWEN (TIS)}

Se recomienda que la elección del tratamiento más adecuado para el manejo de la enfermedad de Bowen (Tis) se haga en función de la edad del paciente, su estado funcional, y el tamaño y la localización anatómica de la lesión.

Se sugiere el uso de las siguientes intervenciones para el manejo de la enfermedad de Bowen:

- Electrodesecación o legrado (curettage)

- Criocirugía

- Cirugía convencional con margen de mínimo $4 \mathrm{~mm}$

DÉBIL, A FAVOR

- Terapia fotodinámica

- 5 -fluorouracilo en concentración al $5 \%$

- Imiquimod en concentración al $5 \%$

Se sugiere emplear la cirugía micrográfica de Mohs para el manejo de la enfermedad de Bowen recurrente, así como en aquellas lesiones localizadas en sitios anatómicos donde se requiera el ahorro de tejido (periorificial, párpados y dedos).

Se sugiere emplear la radioterapia para el manejo de la enfermedad de Bowen, cuando no es posible el manejo quirúrgico u otros métodos previamente descritos.

DÉBIL, A FAVOR

\section{CARCINOMA ESCAMOCELULAR DE BAJO RIESGO (T1)}

Se recomienda el uso de las siguientes técnicas para el manejo del carcinoma escamocelular de bajo riesgo:

- Cirugía convencional con margen de mínimo $4 \mathrm{~mm}$

FUERTE, A FAVOR

- Electrodesecación/curettage

- Criocirugía

Se recomienda emplear la cirugía micrográfica de Mohs para el manejo del carcinoma escamocelular de bajo riesgo, cuando se requiera el ahorro de tejido (periorificial, parpados y dedos), así como en carcinomas recurrentes.

Se sugiere emplear la radioterapia para el manejo del carcinoma escamocelular de bajo riesgo, cuando no es posible el manejo quirúrgico u otros métodos previamente descritos.

DÉBIL, A FAVOR

\section{CARCINOMA ESCAMOCELULAR DE MEDIANO RIESGO (T2A)}

Se recomienda el uso de las siguientes técnicas para el manejo del carcinoma escamocelular de mediano riesgo T2a:

- Cirugía convencional con margen de mínimo $6 \mathrm{~mm}$

- Cirugía micrográfica de Mohs

Se sugiere el uso de la radioterapia en los pacientes con carcinoma escamocelular de piel T2a que no son candidatos quirúrgicos, y como tratamiento adyuvante a la cirugía en carcinomas escamocelulares con bordes comprometidos, no re-operables o con invasión perineural. 
CARCINOMA ESCAMOCELULAR DE ALTO RIESGO (T3-4)

Se recomienda el uso de las siguientes técnicas para el manejo del carcinoma escamocelular de alto riesgo T3-4:

- Cirugía convencional con márgenes amplios.

- Cirugía micrográfica de Mohs.

Se recomienda la valoración de los ganglios regionales en pacientes con carcinoma escamocelular de piel en T3-4, dado su importante riesgo de metástasis.

Se sugiere el uso de la radioterapia en los pacientes con carcinoma escamocelular de piel T3-4 que no son candidatos quirúrgicos, y como tratamiento adyuvante a la cirugía en carcinomas escamocelulares con bordes comprometidos, no re-operables o con invasión perineural.

\section{CARCINOMA ESCAMOCELULAR DE ALTO RIESGO (T2B)}

Se recomienda el uso de las siguientes técnicas para el manejo del carcinoma escamocelular de alto riesgo T2b:

- Cirugía micrográfica de Mohs

- Cirugía convencional con márgenes amplios

Se recomienda la valoración de los ganglios regionales en pacientes con carcinoma escamocelular de piel $\mathrm{T} 2 \mathrm{~b}$, dado su mayor riesgo de metástasis.

FUERTE A FAVOR

CONSENSO

EXPERTOS

DÉBIL A

FAVOR

TABLA 5. Intervenciones quirúrgicas y no quirúrgicas recomendadas para el manejo del carcinoma escamocelular. (Páginas 204 y 205)

de dos años hasta más de cinco años) y la localización anatómica (como aquellos localizados en oídos), afectan la homogeneidad de este resultado.

Lansbury, et al., también evaluaron la recurrencia a ganglios linfáticos regionales reportada por ocho series de casos, la cual osciló entre o y 9,7 \%; la estimación conjunta para este resultado fue de 4,4 \% (IC ${ }_{95 \%} 2,4-6,9$; $\left.\mathrm{I}^{2}=50 \%\right)$. En particular, la recurrencia regional de carcinomas escamocelulares localizados en oídos se estimó en $7,7 \%\left(\mathrm{IC}_{95 \%} 4,8-11,2 ; \mathrm{I}^{2}=0 \%\right)$. Los autores de la revisión sólo encontraron dos series de casos en las cuales se evaluaron metástasis a distancia después de la cirugía, y sólo una de ellas reportó un caso. Asimismo, se evaluó la mortalidad en 485 pacientes pertenecientes a ocho estudios, con cifras de o a 8,1\%; el promedio de muertes estimado por Lansbury, et al., fue 4,1\% (IC ${ }_{95 \%}$ 1,7-7,6; $\mathrm{I}^{2}=58 \%$ ). Sólo en dos estudios se presentaron tiempos de seguimiento superiores a cinco años. Para finalizar, Lansbury, et al., evaluaron el número de escisiones incompletas reportado en 11 estudios con 2.343 escisiones. La estimación promedio de este resultado fue 8,8\% $\left(\mathrm{IC}_{95 \%} 5,4-13 \% ; \mathrm{I}^{2}=89 \%\right.$ ). Los autores encontraron que la definición de este resultado, así como las márgenes empleadas por los cirujanos, no fueron constantes en los estudios incluidos.

En una revisión sistemática de estudios observacio- nales desarrollada por Lansbury, et al. ${ }^{89}$, se evaluó la electrodisecación-legrado (curettage) en ocho estudios de pacientes con carcinoma escamocelular en diferentes estadios; $91 \%$ de los participantes tenía lesiones menores de dos centímetros. Sólo uno de ellos reportó cifras diferenciales para recurrencia local y a distancia, de 15 pacientes con carcinoma escamocelular en el pabellón auricular, de los cuales $20 \%$ tuvo recurrencia local, $7 \%$ tuvo enfermedad regional y dos murieron a causa del carcinoma escamocelular. Para los restantes estudios, los cuales sumaron 1.131 pacientes, se encontraron cifras de recurrencia local o a distancia de 1,7 \% ( IC $_{95 \%}$ $\left.0,6-3,4 ; \mathrm{I}^{2}=59 \%\right)$. Solo en uno de los estudios incluidos en el metanálisis se presentó un seguimiento mayor de cinco años. Sólo en uno de los estudios se reportaron los resultados cosméticos, encontrándose que $54 \%$ de los 41 participantes lo calificaron como "satisfactorio" (CALIDAD MUY BAJA).

Los mismos autores arriba mencionados identificaron nueve estudios referentes a la efectividad de la criocirugía en pacientes con carcinoma escamocelular en diferentes estadios ${ }^{89}$. En ocho estudios se evaluó el resultado de recurrencia después de la criocirugía, estimando los autores un porcentaje conjunto de 0,8\% para este resultado ( $\mathrm{IC}_{95 \%}$ 0,1-2,2; $\mathrm{I}^{2}=0 \%$ ). Ninguno de los estudios incluidos tuvo un seguimiento superior a cinco años. 
En uno de los estudios se reportó un porcentaje de curación de $97 \%$ para 563 lesiones tratadas en un periodo de 23 años. Asimismo, en otro de los estudios se reportó $3 \%$ para el resultado de falla del tratamiento inicial. En ninguno de los estudios identificados se reportaron resultados específicos sobre la apariencia cosmética y los eventos adversos asociados con la intervención (CALIDAD MUY BAJA).

Bath, et al., identificaron un ensayo clínico en pacientes con enfermedad de Bowen en el cual se evaluó la efectividad de la crioterapia Vs. 5-fluoruracilo (5-FU), en el tratamiento de estas lesiones ${ }^{90}$. No encontraron diferencias en el número de lesiones que desaparecieron después del primer ciclo de tratamiento $\left(\mathrm{RR}=0,99 ; \mathrm{IC}_{95 \%}\right.$ $0,78-1,26)$, la recurrencia a los doce meses $\left(R R=1,48 ; I_{95 \%}\right.$ $0,53-4,17)$, el número de lesiones que desaparecieron después del segundo ciclo de tratamiento $\left(\mathrm{RR}=1\right.$; $\mathrm{IC}_{95 \%}$ 0,96-1,04), los resultados cosméticos ( $R R=0,87$; IC $_{95 \%}^{95 \%}$ $0,65-1,17)$ o el reporte de dolor $\left(R R=0,73 ; I_{95 \%} 0,39-1,38\right)$, pero sí en el número de eventos adversos, los cuales fueron menores en el grupo con crioterapia $(R R=0,64$; IC $_{95 \%}$ o, 47-0,86) (CALIDAD BAJA-MODERADA).

De igual manera, en la revisión sistemática de Lansbury, et al. ${ }^{89}$, se evaluó la terapia fotodinámica en 14 estudios que incluyeron 297 pacientes con carcinoma escamocelular en diferentes estadios. Para el resultado de mejoría completa, los investigadores estimaron una proporción de $72 \%\left(\mathrm{IC}_{95 \%} 61,5-81,4 ; \mathrm{I}^{2}=71 \%\right)$. En ocho de los estudios se proporcionaron datos de recurrencia en 199 carcinomas escamocelulares, con un porcentaje conjunto de $26,4 \%$ (IC $_{95 \%} 12,3-43,7 ; \mathrm{I}^{2}=72 \%$ ). La duración promedio de estos seguimientos varió entre 6 y 38 meses. En un estudio se proporcionó información referente a la apariencia cosmética y, 24 meses después del tratamiento, $48 \%$ de los pacientes evaluaron como "bueno" este resultado. No se reportó información referente a eventos adversos en los estudios incluidos (CALIDAD MUY BAJA).

Bath, et al., identificaron siete estudios en que se evaluó la terapia fotodinámica (Photodynamic Therapy, PDT) con metil-amino-levulinato (MAL-PDT) y con ácido aminolevulínico (ALA-PDT), en el tratamiento de la enfermedad de Bowen ${ }^{90}$. En dos estudios se comparó un ciclo de ALAPDT- con dos ciclos de ALA-PDT, separados por un intervalo de dos horas. Los autores de la revisión señalaron que los estudios emplearon metodologías diferentes, ya que uno empleó un ciclo único de ALA-PDT a dosis de 75 J/ $\mathrm{cm}^{2}$ Vs. dos ciclos de $20+80 \mathrm{~J} / \mathrm{cm}^{2}$, mientras que el segundo usó un ciclo único de ALA-PDT a $100 \mathrm{~J} / \mathrm{cm}^{2} V s$. dos ciclos a $50+50 \mathrm{~J} / \mathrm{cm}^{2}$. En uno de los estudios el resultado primario se evaluó usando la intensidad de la fluorescencia. Respecto al número de lesiones que desaparecieron después del primer ciclo de tratamiento, no se encontraron dife- rencias entre las dos intervenciones evaluadas $(R R=0,81$; $\mathrm{IC}_{95 \%}$ 0,62-1,06). No se encontraron diferencias en el número de lesiones con calificación cosmética buena $\left(\mathrm{RR}=1,09 ; \mathrm{IC}_{95 \%} 0,94-1,24\right)$. Tampoco hubo diferencias en el reporte de lesiones dolorosas que requirieron lidocaína $\left(\mathrm{RR}=0,11 ; \mathrm{IC}_{95 \%}\right.$ 0,01-1,96) (CALIDAD BAJA).

Bath, et al., encontraron un estudio en el cual se evaluó la efectividad del imiquimod al $5 \%$ Vs. placebo en crema, en el tratamiento de lesiones de Bowen ${ }^{90}$. Se encontró una mayor proporción de lesiones que desaparecieron con el uso del imiquimod después del primer ciclo de tratamiento (RR calculado por el Grupo Desarrollador de la Guía=19; $\mathrm{IC}_{95 \%}$ 1,2-299). Narrativamente, los autores no reportaron recurrencias a 12 meses en el grupo con imiquimod, mientras que también este tratamiento se asoció con mayor número de reacciones inflamatorias localizadas. Sólo dos pacientes en el grupo con placebo tuvieron progresión a carcinoma escamocelular invasor (12,5\%) (CALIDAD MUY BAJA). Asimismo, en la revisión sistemática de Lansbury, et al. ${ }^{89}$, se evaluó el uso de imiquimod tópico en nueve series de casos de carcinoma escamocelular en diferentes estadios. En ocho de los estudios (12 pacientes en conjunto), se encontró mejoría completa después del tratamiento con confirmación histológica (con excepción de un estudio). Asimismo, en ocho estudios no se encontraron recurrencias después del tratamiento, con seguimientos de seis meses a cuatro años (CALIDAD MUY BAJA).

En dos series de casos adicionales, se evaluó la efectividad del imiquimod en el tratamiento del carcinoma escamocelular. En la primera, se incluyó información de 108 pacientes con 122 tumores, 42 de ellos con carcinoma escamocelular de bajo riesgo, los cuales recibieron imiquimod al $5 \%$ durante una mediana de 12 semanas (2 a 89 semanas) ${ }^{91}$. Al final del seguimiento, se encontró un porcentaje de curación clínica inicial de $100 \%$ de las lesiones de carcinoma escamocelular. Se reportó la recurrencia de un tumor, sin especificar su origen. En la segunda serie de casos, los autores evaluaron 40 pacientes con cáncer de piel no melanoma, 19 de ellos con carcinoma escamocelular, a los cuales se les practicó biopsia o biopsia más curettage, seguida de imiquimod al $5 \%$ una vez al día, cinco veces a la semana durante seis semanas ${ }^{92}$. En el seguimiento de 26 meses, se evaluaron 22 lesiones; un paciente presentó una recurrencia de carcinoma escamocelular y hubo 13,6 \% de reacciones cutáneas calificadas como "significativas” (CALIDAD MUY BAJA).

Por otra parte, en la revisión de Lansbury, et al. ${ }^{89}$, se evaluó el uso de 5-FU intralesional y tópico en cuatro estudios de pacientes con carcinoma escamocelular en diferentes estadios, incluyendo casos de xeroderma pig- 


\section{FUERZA DE LA RECOMENDACIÓN GRADE}

DÉBIL, A FAVOR
"SE SUGIERE EMPLEAR LA RADIOTERAPIA PARA EL MANEJO DE LA ENFERMEDAD DE BOWEN, CUANDO NO ES POSIBLE EL MANEJO QUIRÚRGICO U OTROS MÉTODOS PREVIAMENTE DESCRITOS". mentoso. Sobre el uso intralesional de 5-FU, se encontró un estudio piloto de 23 pacientes, en el cual se reportó curación completa en 22 pacientes (96\%), 16 semanas después de la finalización del tratamiento. Asimismo, la calificación del resultado cosmético fue de "buena a excelente", según los médicos tratantes y los pacientes, en 91 y $100 \%$ de los casos, respectivamente. En un reporte de caso, tampoco se encontraron recurrencias a cinco meses después del tratamiento. En estos estudios, el resultado de recurrencia no fue evaluado. Respecto al 5-FU tópico, en una serie de casos de 53 pacientes con carcinoma escamocelular, se observó regresión del tumor en $79 \%$ de los casos, después del tratamiento con concentraciones de 5, 10 y $20 \%$, en tres ciclos. Al año no se encontraron recurrencias del carcinoma escamocelular. En una segunda serie de casos de xeroderma pigmentoso, se reportó que 7 de 10 pacientes presentaron regresión superficial, sin que se evaluara la recurrencia posterior (CALIDAD MUY BAJA).

Bath, et al., evaluaron la efectividad de la crioterapia Vs. 5-FU, en el tratamiento de la enfermedad de Bowen ${ }^{90}$. No encontraron diferencias en el número de lesiones que desaparecieron después del primer ciclo de tratamiento ( $\left.\mathrm{RR}=0,99 ; \mathrm{IC}_{95 \%} \mathrm{O}, 78-1,26\right)$, en la recurrencia a los doce meses ( $R R=1,48 ; I_{95 \%} 0,53-4,17$ ), en el número de lesiones que desaparecieron después del segundo ciclo de tratamiento $\left(\mathrm{RR}=1 ; \mathrm{IC}_{95 \%} 0,96-1,04\right)$, en los resultados cosméticos ( $\left.R R=0,87 ; \mathrm{IC}_{95 \%} 0,65-1,17\right)$ ni en el reporte de dolor ( $\left.\mathrm{RR}=0,73 ; \mathrm{IC}_{95 \%} 0,39-1,38\right)$, pero sí en el número de eventos adversos, los cuales fueron menores en el grupo

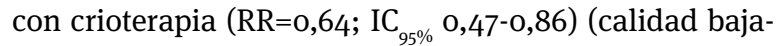
moderada). En una serie adicional de casos, se evaluó la efectividad del 5-FU por vía oral en el tratamiento de 14 pacientes con edad promedio de 76,5 años, los cuales presentaban lesiones agresivas, múltiples o recurrentes de carcinoma escamocelular ${ }^{93}$. Los pacientes recibieron 175 $\mathrm{mg} / \mathrm{m}^{2}$ al día de 5 -FU por vía oral durante tres semanas, cada cinco semanas, en un promedio de cuatro ciclos ( 2 a 6 ciclos). De los 14 pacientes, 9 (64,3\%) tuvieron mejoría clínica con mediana de duración de 30 meses, entendida como: remisión parcial (2), remisión mínima (3) o detención de la enfermedad (4) (CALIDAD MUY BAJA).

En la revisión sistemática de estudios observacionales desarrollada por Lansbury, et al. (89), se evaluó la cirugía micrográfica de Mohs en 16 estudios de carcinoma escamocelular en diferentes estadios, practicada por motivos como la localización del tumor, el tamaño del tumor y su pobre definición, entre otros. Respecto al resultado de curación a los cinco años, el análisis conjunto de 2.133 lesiones en varios sitios (incluidos orejas y parpados), derivó en un porcentaje estimado de 97,4 \% ( IC $_{95 \%} 96,2-98,3$; $\mathrm{I}^{2}=48 \%$ ). Se analizó la recurrencia local en 10 estudios con 1.572 pacientes, estimándose una proporción conjunta de 3,0 \% ( IC $_{95 \%} 2,2-3,9 ; \mathrm{I}^{2}=0 \%$ ). Sólo en dos estudios hubo un seguimiento mayor de cinco años. Se informó la recurrencia en ganglios linfáticos regionales en seis estudios con 1.162 pacientes, y se estimó una proporción de esta recurrencia de 4,2 \% $\left(\mathrm{IC}_{95 \%} 2,3-6,6 ; \mathrm{I}^{2}=56 \%\right)$. En este caso, la mayor parte de los estudios tuvo seguimientos entre dos y cinco años.

En dos series de casos no se encontraron metástasis a distancia con seguimientos de cinco y de tres años, mientras que, en otras dos series de casos de tamaño muestral pequeño, se encontró un caso en cada una.

Además, en cuatro estudios hubo muertes asociadas con el carcinoma escamocelular, con una estimación conjunta de 1,1 \% ( IC $_{95 \%} 0,3-5,4 ; \mathrm{I}^{2}=61 \%$ ). En ninguno de los estudios se informó sobre la calidad de vida, los resultados cosméticos o los eventos adversos.

Finalmente, en la revisión sistemática de Lansbury, et $a l .{ }^{89}$, se evaluaron la radioterapia externa y la braquiterapia en el tratamiento del carcinoma escamocelular en diferentes estadios, incluyendo pacientes con enfermedad de Bowen, con tumores de localización anató- 


\section{SEGUIMIENTO DE PACIENTES}

Se recomienda el seguimiento clínico de los pacientes con carcinoma escamocelular, de la siguiente forma:

- En carcinoma escamocelular in situ (enfermedad de Bowen) y carcinoma escamocelular de bajo riesgo ( $\mathrm{T}_{1}$ ), debe hacerse cada cuatro meses el primer año, cada seis meses el segundo año y, a partir del tercer año, anualmente hasta los cinco años.

- En carcinoma escamocelular de mediano y alto riesgo (T2a, T2b, T3 y T4), debe hacerse cada tres meses durante los dos primeros años y, después, de manera anual hasta los cinco años.

Se recomienda que todos los pacientes con carcinoma escamocelular de piel reciban indicaciones respecto al autoexamen del sitio intervenido, la piel circundante y los ganglios linfáticos, así como información sobre qué hacer ante la sospecha de recurrencia.

CONSENSO DE EXPERTOS

PUNTO

DE BUENA

PRÁCTICA

CLÍNICA

TABLA 6. Seguimiento de pacientes con carcinoma escamocelular.

mica de difícil abordaje y de alto riesgo, entre otros. Respecto al uso de la radioterapia externa, Lansbury, et al., encontraron 14 estudios retrospectivos con 1.018 lesiones de carcinoma escamocelular. En siete estudios se reportaron datos de recurrencia local en 761 pacientes, estimando un porcentaje global de $6,4 \%$ para este resultado (IC ${ }_{95 \%} 3,0-11,0 ; I^{2}=76 \%$ ). En ninguno de los estudios encontrados se hizo un seguimiento mayor de cinco años. Por otra parte, en tres estudios se informó recurrencia en ganglios linfáticos regionales, con un porcentaje conjunto de recurrencia de $2,6 \%\left(\mathrm{IC}_{95 \%} \mathrm{O}, 04-8,9 ; \mathrm{I}^{2}=70\right)$. En un estudio se reporto $30 \%$ de recurrencia local o regional en 37 pacientes con tumores clasificados desde $\mathrm{T}_{2}$ hasta $\mathrm{T}_{4}$. Asimismo, en cinco estudios con 191 pacientes, se reportaron muertes asociadas con carcinoma escamocelular, estimando los autores de la revisión una mortalidad de $9,1 \%\left(\mathrm{IC}_{95 \%} 1,4-22,8 ; \mathrm{I}^{2}=79 \%\right)$. En ninguno de los estudios se informó sobre la calidad de vida, los resultados cosméticos o los eventos adversos.

En la revisión, se encontraron seis estudios con 88 lesiones de carcinoma escamocelular, en los cuales se informó recurrencia después de braquiterapia, en un porcentaje estimado de $5,2 \%$ (IC ${ }_{95 \%} 1,6-10,5 ; I^{2}=0 \%$ ). Los seguimientos variaron entre 9,6 y 55 meses en dichos estudios. En cuatro de estos estudios no se presentaron recurrencias después de finalizar el tratamiento y en ninguno de los ocho estudios se presentaron datos sobre metástasis regional o a distancia. Nuevamente, en ninguno se informó sobre la calidad de vida, los resultados cosméticos o los eventos adversos (CALIDAD MUY BAJA).

\section{9. ¿Cómo debe hacerse el seguimiento de pacientes con carcinoma escamocelular?}

(Para una síntesis de las recomendaciones, ver la TABLA 6) La guía de práctica clínica del 2009 de la British Association of Dermatologist, establece que todos los pacientes deben ser instruidos en el autoexamen del sitio intervenido, de la piel circundante y de los ganglios linfáticos, así como recibir información sobre qué hacer ante la sospecha de recurrencia ${ }^{94}$. El seguimiento de estos pacientes puede ser llevado a cabo por un especialista, o por un médico general o una enfermera entrenados para tal fin. Asimismo, los pacientes en alto riesgo deben estar en observación médica por lo menos durante dos años y hasta cinco años (CALIDAD No valORABLE). Asimismo, en la guía australiana de práctica clínica sobre cáncer de piel no melnoma, se indica que todos los pacientes bajo tratamiento para esta condición deben tener un seguimiento para identificar la recurrencia, las metástasis o la aparición de nuevos cánceres primarios de piel. Los autores afirman que el médico general puede hacer este seguimiento, solicitando consultas especializadas ante cualquier duda en particular ${ }^{95}$ (CALIDAD NO VALORABLE).

\section{AGRADECIMIENTOS}

Un agradecimiento especial a Mariam Carolina Rolón, especialista en Dermatopatología y Patología Oncoló- 
gica, Instituto Nacional de Cancerología, Bogotá, D.C., Colombia; Enrique Cadena, especialista en Cirugía de Cabeza y Cuello, Instituto Nacional de Cancerología, Bogotá, D.C., Colombia, y Victoria Eugenia Franco, Especialista en Dermatología, Centro Dermatológico Federico Lleras Acosta, Bogotá, D.C., Colombia

\section{ACTUALIZACIÓN DE LA GuÍA dE ATENCIÓN INTEGRAL}

Debido a que no existe consenso sobre cuál debe ser el tiempo que debe transcurrir para la actualización de una guía de práctica clínica, el grupo desarrollador considera que estos procesos deben ocurrir según se requieran, teniendo en cuenta la generación de nueva 'evidencia' científica que pueda modificar o generar nuevas recomendaciones. Dado que en esta guía no se abordan algunos aspectos de la atención integral del paciente con cáncer de piel no melanoma, deben facilitarse procesos que permitan la generación de recomendaciones al respecto.

El grupo desarrollador considera que la actualización de esta guía de práctica clínica debe darse antes de cinco años. Sin embargo, las recomendaciones complementarias a las aquí descritas y las que considere pertinentes el Ministerio de Salud y Protección Social, pueden modificarse o actualizarse en un tiempo más corto, dependiendo no solo de las necesidades observadas, sino de los cambios en el conocimiento.

\section{FUENTE DE FINANCIACIÓN}

Este documento se ha elaborado en el marco de la Convocatoria 563/2012 de Colciencias, bajo la dirección de la Fundación Universitaria de Ciencias de la Salud y el Instituto Nacional de Cancerología, y el soporte científico de la Asociación Colombiana de Dermatología y Cirugía Dermatológica y el Centro Dermatológico Federico Lleras Acosta. El propósito de la convocatoria fue la elaboración de una "Guía de atención integral en cáncer de piel no melanoma: carcinoma escamocelular” para el Ministerio de Salud y Protección Social, la cual está compuesta por una guía de práctica clínica basada en la 'evidencia' en sus versiones completa y de rápida referencia, un grupo de evaluaciones económicas y una guía informativa para pacientes y cuidadores.

Financiación: Programa Nacional de Ciencia, Tecnología e Innovación en Salud, Departamento Administrativo de Ciencia Tecnología e Innovación en Salud, Colciencias, Convocatoria 563/2012, Contrato 469-2012, Código de proyecto 5007-563-35261

\section{CONFLICTOS DE INTERESES}

A partir del momento en el que se estructuró la propuesta y se conformó el Grupo Desarrollador de la Guía, se declararon y evaluaron los posibles conflictos de intereses. Una vez la propuesta fue aprobada para su ejecución, nuevamente, y basados en lo planteado por la "Guía metodológica para la elaboración de guías de práctica clínica con evaluación económica en el Sistema de General de Seguridad Social en Salud colombiano" del Ministerio de Salud y Protección Social, el grupo de expertos clínicos, expertos en metodología y el equipo de evaluación económica revisaron y declararon sus posibles conflictos de intereses. Un comité ad hoc revisó cada caso y se pronunció frente al particular. Los detalles se presentan en la versión completa de la presente guía.

\section{DECLARACIÓN DE INDEPENDENCIA EDITORIAL}

La información y los datos contenidos en esta guía de práctica clínica son resultado de un riguroso proceso de investigación, realizado de manera independiente por el Grupo Desarrollador, el cual estuvo integrado por investigadores de la Fundación Universitaria de Ciencias de la Salud, el Instituto Nacional de Cancerología, el Centro Dermatológico Federico Lleras Acosta E.S.E, y algunos miembros de la Asociación Colombiana de Dermatología y Cirugía Dermatológica. El ente financiador hizo seguimiento a la elaboración del presente documento garantizando la libertad no condicionada de los contenidos de la guía. Todos los miembros del Grupo Desarrollador, participantes directos de los procesos de desarrollo, y las personas que participaron en la revisión externa realizaron la declaración de conflictos de interés.

\section{DERECHOS DE AUTOR}

De acuerdo con el Artículo 20 de la Ley 23 de 1982, los derechos patrimoniales de esta obra pertenecen al Ministerio de Salud y Protección Social y al Departamento de Ciencia, Tecnología e Innovación (Colciencias), sin perjuicio de los derechos morales a los que haya lugar, de acuerdo con el Artículo 30 de la misma ley. Esta guía hace parte de un grupo de guías de práctica clínica que incorporan consideraciones económicas y de implementabilidad en el contexto del Sistema General de Seguridad Social en Salud colombiano, que se desarrollaron por iniciativa del Ministerio de la Salud y Protección Social en temas prioritarios y de alta prevalencia en el país. 


\section{GRUPO DESARROLLADOR DE LA GUÍA}

\section{EXPERTOS TEMÁTICOS}

\begin{abstract}
Álvaro Enrique Acosta Madiedo De Hart
Especialista en Dermatología, Especialista en Dermatología Oncológica y Cirugía Dermatológica. Coordinador, Dermatología, Instituto Nacional de Cancerología. Profesor asociado, Universidad Nacional de Colombia. Investigador principal. Líder clínico de la Guías de Práctica Clínica de Carcinoma Basocelular, Carcinoma Escamocelular y Queratosis Actínica.
\end{abstract}

\section{Xavier Rueda Cadena}

Especialista en Dermatología, Especialista en Dermatología Oncológica. Instituto Nacional de Cancerología. Coinvestigador Guía de Práctica Clínica de Carcinoma Basocelular. Coordinador clínico de las Guías de Carcinoma Escamocelular y Queratosis Actínica.

\section{John Alexander Nova Villanueva}

Especialista en Dermatología, Magíster en Epidemiología Clínica, Centro Dermatológico Federico Lleras Acosta, CDFLLA. Coinvestigador de las Guías de Práctica Clínica de Carcinoma Escamocelular y Queratosis Actínica. Coordinador clínico, Guía de Práctica Clínica de Carcinoma Basocelular.

\section{Martha Cecilia Valbuena Mesa}

Especialista en Dermatología, Especialista en Fotodermatología, Centro Dermatológico Federico Lleras Acosta, CDFLLA. Coinvestigadora de las Guías de Práctica Clínica de Carcinoma Basocelular, Carcinoma Escamocelular y Queratosis Actínica.

\section{Hugo Eduardo Herrera Nossa}

Especialista en Dermatología, Asociación Colombiana de Dermatología y Cirugía Dermatológica, Asocolderma, Universidad El Bosque. Coinvestigador de las Guías de Práctica Clínica de Carcinoma Basocelular, Carcinoma Escamocelular y Queratosis Actínica.

\section{Ana Francisca Ramírez Escobar \\ Especialista en Dermatología, Especialista en Dermato- logía Oncológica, Asociación Colombiana de Dermatología y Cirugía Dermatológica, Asocolderma. Coinvestigadora de las Guías de Práctica Clínica de Carcinoma Basocelular, Carcinoma Escamocelular y Queratosis Actínica.}

\section{Victoria Eugenia Franco Correa}

Especialista en Dermatología, Centro Dermatológico Federico Lleras Acosta, CDFLLA. Coinvestigadora de las
Guías de Práctica Clínica de Carcinoma Basocelular, Carcinoma Escamocelular y Queratosis Actínica.

\section{Guillermo Jiménez Calfat}

Especialista en Dermatología, Especialista en Dermatología Oncológica y Cirugía Dermatológica, Asociación Colombiana de Dermatología y Cirugía Dermatológica, Asocolderma. Coinvestigador de las Guías de Práctica Clínica de Carcinoma Basocelular, Carcinoma Escamocelular y Queratosis Actínica.

\section{Mariam Carolina Rolón Cadena}

Especialista en Dermatopatología. Patóloga oncóloga, Instituto Nacional de Cancerología. Coinvestigadora de las Guías de Práctica Clínica de Carcinoma Basocelular, Carcinoma Escamocelular y Queratosis Actínica.

\section{Enrique Cadena Piñeros}

Especialista en Cirugía de Cabeza y Cuello, Instituto Nacional de Cancerología, Coinvestigador de las Guías de Práctica Clínica de Carcinoma Basocelular, Carcinoma Escamocelular y Queratosis Actínica.

\section{EQUIPO METODOLÓGICO}

\section{Guillermo Sánchez Vanegas}

Especialista en Epidemiología General, Magíster en Epidemiología Clínica, Doctor en Salud Pública. Fundación Universitaria de Ciencias de la Salud, FUCS. Coordinador Metodológico de las Guías de Práctica Clínica de Carcinoma Basocelular, Carcinoma Escamocelular y Queratosis Actínica.

\section{Andrea Esperanza Rodríguez Hernández}

Especialista en Estadística Aplicada, Magíster en Epidemiología Clínica. Fundación Universitaria de Ciencias de la Salud, FUCS. Coordinadora metodológica y epidemióloga senior de la Guía de Práctica Clínica de Carcinoma Basocelular. Coinvestigadora de las Guías de Práctica Clínica de Carcinoma Escamocelular y Queratosis Actínica. Equipo de Plan de Implementación e Indicadores de las Guías de Práctica Clínica de Carcinoma Basocelular, Carcinoma Escamocelular y Queratosis Actínica.

\section{Ingrid Arévalo Rodríguez}

Magíster en Epidemiología Clínica, PhD (c) Medicina Preventiva y Salud Pública, Fundación Universitaria de Ciencias de la Salud, FUCS. Coordinadora metodológica y epidemióloga senior de las Guías de Práctica Clínica de Carcinoma Escamoceluar y Queratosis Actínica.Coinvestigadora de la Guía de Práctica Clínica de Carcinoma Basocelular. 


\begin{abstract}
Magda Cepeda Gil
Magíster en Epidemiología Clínica. Fundación Universitaria de Ciencias de la Salud, FUCS. Epidemióloga de la Guía de Práctica Clínica de Carcinoma Basocelular. Epidemióloga coinvestigadora de las Guías de Práctica Clínica de Carcinoma Escamocelular y Queratosis Actínica.
\end{abstract}

\section{Omar Darío Segura}

Magíster en Epidemiología Clínica, Epidemiólogo de Campo, PhD (C) en Salud Pública. Fundación Universitaria de Ciencias de la Salud, FUCS. Epidemiólogo de las Guías de Práctica Clínica de Carcinoma Escamocelular y Queratosis Actínica. Epidemiólogo coinvestigador de la Guía de Práctica Clínica de Carcinoma Basocelular.

\section{Celmira Laza Vásquez}

Especialista en Epidemiología General, Máster en Enfermería, Fundación Universitaria de Ciencias de la Salud, FUCS. Coordinadora, Componente Cualitativo de Participación de Pacientes. Coinvestigadora de las Guías de Práctica Clínica de Carcinoma Basocelular, Carcinoma Escamocelular y Queratosis Actínica.

\section{Mónica Patricia Ballesteros Silva}

Especialista en Epidemiología General, Máster en Epidemiología Clínica, Máster en Salud Pública. PhD (C) en Medicina Preventiva y Salud Pública. Centro Cochrane Iberoamericano. Redactor general de las Guías de Práctica Clínica de Carcinoma Basocelular, Carcinoma Escamocelular y Queratosis Actínica.

\section{EQUIPO DE EVALUACIÓN ECONÓMICA}

\section{Óscar Gamboa Garay}

Especialista en Estadística, Magíster en Economía. Fundación Universitaria de Ciencias de la Salud, FUCS. Instituto Nacional de Cancerología. Coordinador, Componente de Evaluación Económica de las Guías de Práctica Clínica de Carcinoma Basocelular, Carcinoma Escamocelular y Queratosis Actínica.

\section{Carlos Adolfo Gamboa Garay}

Economista, Instituto Nacional de Cancerología.

Coinvestigador del Equipo de Evaluación Económica de las Guías de Práctica Clínica deCarcinoma Basocelular, Carcinoma Escamocelular y Queratosis Actínica.

\section{Teófilo Lozano Apache}

Ingeniero industrial, Especialista en Estadística, Instituto Nacional de Cancerología.

Coinvestigador del Equipo de Evaluación Económica de las Guías de Práctica Clínica de Carcinoma Basocelular, Carcinoma Escamocelular y Queratosis Actínica.

\section{Ana Milena Gil Quijano}

Fonoaudióloga, Magíster en Salud y Seguridad en el Trabajo. Instituto Nacional de Cancerología

Coinvestigadora del Equipo de Evaluación Económica de las Guías de Práctica Clínica de Carcinoma Basocelular, Carcinoma Escamocelular y Queratosis Actínica

\section{ESTUDIANTES DE POSTGRADO VINCULADOS AL GRUPO DESARROLLADOR}

\section{Mauricio Gamboa Arango.}

Residente de Dermatología.Fundación Universitaria Sanitas. Aprendizaje en desarrollo de Guías de Atención Integral.

\section{Jenny González Arboleda}

Residente de Dermatología, Fundación Universitaria de Ciencias de la Salud, FUCS. Aprendizaje en desarrollo de Guías de Atención Integral.

\section{Claudia Ximena Carvajal Montoya}

Residente de Dermatología, Fundación Universitaria Sanitas. Centro Dermatológico Federico Lleras Acosta, CDFLLA. Aprendizaje en desarrollo de Guías de Atención Integral.

\section{Carolina Solórzano}

Residente de Dermatología, Fundación Universitaria de Ciencias de la Salud, FUCS.

Aprendizaje en desarrollo de Guías de Atención Integral.

\section{Dirección y coordinación}

Guillermo Sánchez Vanegas, Especialista en Epidemiología General. Magíster en Epidemiología Clínica. Doctor en Salud Pública. Fundación Universitaria de Ciencias de la Salud, FUCS. Director de las Guías de Práctica Clínica de Carcinoma Basocelular, Carcinoma Escamocelular y Queratosis Actínica.

\section{Diana Carolina Buitrago García}

Enfermera, Especialización en Epidemiología Clínica, Fundación Universitaria de Ciencias de la Salud, FUCS. Coordinadora administrativa de las Guías de Práctica Clínica de Carcinoma Basocelular, Carcinoma Escamocelular y Queratosis Actínica.

\section{ASISTENTES ADMINISTRATIVOS}

\section{Yuli Paola Agudelo Camargo}

Fundación Universitaria de Ciencias de la Salud, FUCS, marzo a diciembre de 2013.

\section{Leidy Johanna León Murcia}

Fundación Universitaria de Ciencias de la Salud, FUCS. 


\section{REFERENCIAS}

1. Lauth $\mathrm{M}$, Unden $\mathrm{AB}$, Toftgård $\mathrm{R}$. Non-melanoma skin cancer: Pathogenesis and mechanisms. Drug Discov Today Dis Mech . 2004;1:267-72.

2. Bowden GT. Prevention of non-melanoma skin cancer by targeting ultraviolet-B-light signalling. Nat Rev Cancer. 2004;4:23-35.

3. Staples M, Marks R, Giles G. Trends in the incidence of nonmelanocytic skin cancer (NMSC) treated in Australia 1985-1995: Are primary prevention programs starting to have an effect? Int J Cancer. 1998;78:144-8.

4. Diepgen TL, Mahler V. The epidemiology of skin cancer. Br J Dermatol. 2002;146(Suppl.61):1-6.

5. Green A. Changing patterns in incidence of non-melanoma skin cancer. Epithelial Cell Biol. 1992;1:47-51.

6. Glass AG, Hoover RN. The emerging epidemic of melanoma and squamous cell skin cancer. JAMA. 1989;262:2097-100.

7. Holme SA, Malinovszky K, Roberts DL. Changing trends in nonmelanoma skin cancer in South Wales, 1988-98. Br J Dermatol. 2000;143:1224-9.

8. Staples MP, Elwood M, Burton RC, Williams JL, Marks R, Giles GG. Non-melanoma skin cancer in Australia: The 2002 national survey and trends since 1985. Med J Aust. 2006;184:6-10.

9. Bielsa I, Soria X, Esteve M, Ferrandiz C. Population-based incidence of basal cell carcinoma in a Spanish Mediterranean area. Br J Dermatol. 2009;161:1341-6.

10. Aceituno-Madera P, Buendia-Eisman A, Arias-Santiago S, Serrano-Ortega S. Evolución de la incidencia del cáncer de piel en el periodo 1978-2002. Actas Dermosifiliog. 2010;101:39-46.

11. Lomas A, Leonardi-Bee J, Bath-Hextall F. A systematic review of worldwide incidence of nonmelanoma skin cancer. Br J Dermatol. 2012;166:1069-80.

12. Sánchez GN, De la Hoz J, Castañeda F. Incidencia de cáncer de piel en Colombia. Años 2003-2007. Piel. 2011;26:171-7.

13. Instituto Nacional de Cancerología. Anuario Estadístico 2009. Bogotá: Legis; 2010.

14. Nova-Villanueva J, Sánchez-Vanegas G, Porras de Quintana L. Cancer de Piel: Perfil Epidemiologico de un Centro de Referencia en Colombia 2003-2005. Rev Salud Pública (Bogotá). 2007;9:595-601.

15. Lewis KG, Weinstock MA. Nonmelanoma skin cancer mortality (1988-2000): The Rhode Island follow-back study. Arch Dermatol. 2004;140:837-42.

16. Abadia CE, Oviedo DG. Bureaucratic itineraries in Colombia. A theoretical and methodological tool to assess managed-care health care systems. Soc Sci Med. 2009;68:1153-6o.

17. Seretis K, Thomaidis V, Karpouzis A, Tamiolakis D, Tsamis I. Epidemiology of surgical treatment of nonmelanoma skin cancer of the head and neck in Greece. Dermatol Surg. 2010;36:15-22.

18. Ministerio de la Protección Social-Colciencias-CEIS. Guía metodológica para la elaboración de guías de atención integral en el Sistema General de Seguridad Social en Salud Colombiano. Bogotá: Ministerio de la Protección Social; 2010.

19. Ministerio de la Protección Social-Colciencias-CEIS. Guía metodológica para la elaboración de guías de práctica clínica con evaluación económica en el Sistema General de Seguridad Social en Salud Colombiano Bogotá: Fundación Santafe de Bogotá-Centro de Estudios e Investigación en Salud; 2013.
20. Grupo de trabajo de la Guía de Práctica Clínica sobre Atención al Parto Normal. Guía de Práctica Clínica sobre la Atención al Parto Normal. Bilbao: Plan de Calidad para el Sistema Nacional de Salud del Ministerio de Sanidad y Política Social. Agencia de Evaluación de Tecnologías Sanitarias del País Vasco (OSTEBA). Agencia de Evaluación de Tecnologías Sanitarias de Galicia (Avalia-t). Fecha de consulta: $1^{0}$ de junio de 2011. Disponible en: http://portal.guiasalud.es/web/ guest/catalogo-gpc?p_p_id=EXT_8_INSTANCE_YIe8\&p_p lifecycle $=0 \& p \quad p$ state $=$ maximized $\& p \quad p$ mode $=$ view $\& p p$ col id=column- $3 \& p$ p col pos $=1 \& p$ p col count $=2 \&$ EXT 8 INSTANCE_YIe8_struts_action $=\% 2 \mathrm{Fext} \% 2 \mathrm{Fpredisenyada} \% 2 \mathrm{~F}$ vista_Previa\&_EXT_8_INSTANCE_YIe8_contenidoId $=57717 \&$ EXT 8 INSTANCE YIe8 version=1.5.

21. Green AC, McBride P. Squamous cell carcinoma of the skin (nonmetastatic). BMJ Clin Evid. 2010;2010.

22. Pavlovic S, Wiley E, Guzmán G, Morris D, Braniecki M. Marjolin ulcer: an overlooked entity. Int Wound J. 2011;8:419-24.

23. Schmitt J, Seidler A, Diepgen TL, Bauer A. Occupational ultraviolet light exposure increases the risk for the development of cutaneous squamous cell carcinoma: A systematic review and meta-analysis. Br J Dermatol. 2011;164:291-307.

24. Johnson TM, Rowe DE, Nelson BR, Swanson NA. Squamous cell carcinoma of the skin (excluding lip and oral mucosa). J Am Acad Dermatol. 1992;26(Pt 2):467-84.

25. Scotto J, Fears TR. Skin cancer epidemiology: Research needs. National Cancer Institute monograph. 1978;50:169-77.

26. Armstrong BK, Kricker A. The epidemiology of UV induced skin cancer. J Photochem Photobiol B. 2001;63:8-18.

27. Zanetti R, Rosso S, Martínez C, Navarro C, Schraub S, SanchoGarnier H, et al. The multicentre south European study 'Helios'. I: Skin characteristics and sunburns in basal cell and squamous cell carcinomas of the skin. Br J Cancer. 1996;73:1440-6.

28. Han J, Colditz GA, Hunter DJ. Risk factors for skin cancers: A nested case-control study within the Nurses' Health Study. Int J Epidemiol. 2006;35:1514-21.

29. Kricker A, Armstrong BK, English DR, Heenan PJ. Pigmentary and cutaneous risk factors for non-melanocytic skin cancer--a case-control study. Int J Cancer. 1991;48:650-62.

30. Sánchez $\mathrm{G}$, Nova J. Risk factors for squamous cell carcinoma, a study by the National Dermatology Centre of Colombia. Actas Dermosifiliog. 2013;104:672-8.

31. Lear JT, Tan BB, Smith AG, Bowers W, Jones PW, Heagerty AH, et al. Risk factors for basal cell carcinoma in the UK: Case-control study in 806 patients. J R Soc Med. 1997;90:371-4.

32. Walther U, Kron M, Sander S, Sebastian G, Sander R, Peter RU, et al. Risk and protective factors for sporadic basal cell carcinoma: Results of a two-centre case-control study in southern Germany. Clinical actinic elastosis may be a protective factor. $\mathrm{Br}$ J Dermatol. 2004;151:170-8.

33. Gawkrodger DJ. Occupational skin cancers. Occup Med. 2004;54:485-463.

34. De Hertog SA, Wensveen Ca Fau - Bastiaens MT, Bastiaens M Fau - Kielich CJ, Kielich Cj Fau - Berkhout MJ, Berkhout Mj Fau Westendorp RG, Westendorp Rg Fau - Vermeer BJ, et al. Relation between smoking and skin cancer. J Clin Oncol . 2001;19:231-238.

35. Tessari G, Girolomoni G. Nonmelanoma skin cancer in solid organ transplant recipients: Update on epidemiology, risk factors, and management. Dermatol Surg. 2012;38:1622-1630. 
36. Lobo DV, Chu P, Grekin RC, Berger TG. Nonmelanoma skin cancers and infection with the human immunodeficiency virus. Arch Dermatol. 1992;128:623-7.

37. Stromberg BV, Keiter JE, Wray RC, Weeks PM. Scar carcinoma: Prognosis and treatment. South Med J. 1977;70:821-2.

38. Edwards MJ, Hirsch RM, Broadwater JR, Netscher DT, Ames FC. Squamous cell carcinoma arising in previously burned or irradiated skin. Arch Surg. 1989;124:115-7.

39. Lohmann CM, Solomon AR. Clinicopathologic variants of cutaneous squamous cell carcinoma. Adv Anat Pathol. 2001;8:27-36.

40. Cox NH. Body site distribution of Bowen's disease. Br J Dermatol. 1994;130:714-6.

41. Eedy DJ, Gavin AT. Thirteen-year retrospective study of Bowen's disease in Northern Ireland. Br J Dermatol. 1987;117:715-20.

42. Kossard S, Rosen R. Cutaneous Bowen's disease. An analysis of 1001 cases according to age, sex, and site. J Am Acad Dermatol. 1992;27:406-10.

43. Thestrup-Pedersen K, Ravnborg L, Reymann F. Morbus Bowen. A description of the disease in 617 patients. Acta Derm Venereolog. 1988;68:236-9.

44. Cox NH, Eedy DJ, Morton CA. Guidelines for management of Bowen's disease: 2006 update. Br J Dermatol. 2007;156:11-21.

45. Sharma A, Schwartz RA, Swan KG. Marjolin’s warty ulcer. J Surg Oncol. 2011;103:193-5.

46. Vandeweyer E, Sales F, Deraemaecker R. Cutaneous verrucous carcinoma. Br J Plast Surg. 2001;54:168-70.

47. Kossard S, Tan KB, Choy C. Keratoacanthoma and infundibulocystic squamous cell carcinoma. Am J Dermatopathol. 2008;30:127-34.

48. Nghiem P, Prieto, VG, Frishberg D. Protocol for the examination of specimens from patients with squamous cell carcinoma of the skin. Protocol applies to invasive squamous cell carcinomas of the skin. Squamous cell carcinomas of the eyelid, vulva, and penis are not included. Northfield; IL: College of American Pathologists; 2013.

49. Abar BW, Turrisi R, Hillhouse J, Loken E, Stapleton J, Gunn H. Preventing skin cancer in college females: Heterogeneous effects over time. Health Psychol. 2010;29:574-82.

50. Armstrong AW, Watson AJ, Makredes M, Frangos JE, Kimball $\mathrm{AB}$, Kvedar JC. Text-message reminders to improve sunscreen use: A randomized, controlled trial using electronic monitoring. Arch Dermatol. 2009;145:1230-6.

51. Crane LA, Schneider LS, Yohn JJ, Morelli JG, Plomer KD. “Block the sun, not the fun": Evaluation of a skin cancer prevention program for child care centers. Am J Prev Med. 1999;17:31-7.

52. Sancho-Garnier H, Pereira B, Cesarini P. A cluster randomized trial to evaluate a health education programme "Living with Sun at School”. Int J Environ Res Public Health. 2012;9:2345-61.

53. Buller DB, Reynolds KD, Ashley JL, Buller MK, Kane IL, Stabell CL, et al. Motivating public school districts to adopt sun protection policies: A randomized controlled trial. Am J Prev Med. 2011;41:309-16.

54. Crane LA, Asdigian NL, Baron AE, Aalborg J, Marcus AC, Mokrohisky ST, et al. Mailed intervention to promote sun protection of children: A randomized controlled trial. Am J Prev Med. 2012;43:399-410.

55. Pagoto SL, Schneider KL, Oleski J, Bodenlos JS, Ma Y. The sunless study: A beach randomized trial of a skin cancer prevention intervention promoting sunless tanning. Arch Dermatol. 2010;146:979-84.
56. Hunter S, Love-Jackson K, Abdulla R, Zhu W, Lee JH, Wells KJ, et al. Sun protection at elementary schools: A cluster randomized trial. J Natl Cancer Inst. 2010;102:484-92.

57. Zhang M, Qureshi AA, Geller AC, Frazier L, Hunter DJ, Han J. Use of tanning beds and incidence of skin cancer. J Clin Oncol. 2012;30:1588-93.

58. Karagas MR, Stannard VA, Mott LA, Slattery MJ, Spencer SK, Weinstock MA. Use of tanning devices and risk of basal cell and squamous cell skin cancers. J Natl Cancer Inst. 2002;94:224-6.

59. Autier P, Dore JF, Negrier S, Lienard D, Panizzon R, Lejeune FJ, et al. Sunscreen use and duration of sun exposure: A doubleblind, randomized trial. J Natl Cancer Inst. 1999;91:1304-9.

6o. van der Pols JC, Williams GM, Neale RE, Clavarino A, Green AC. Long-term increase in sunscreen use in an Australian community after a skin cancer prevention trial. Prev Med. 2006;42:171-6.

61. Seite S, Moyal D, Verdier MP, Hourseau C, Fourtanier A. Accumulated p53 protein and UVA protection level of sunscreens. Photodermatol Photoimmunol Photomed. 2000;16:3-9.

62. Green A, Williams G, Neale R, Hart V, Leslie D, Parsons P, et al. Daily sunscreen application and betacarotene supplementation in prevention of basal-cell and squamous-cell carcinomas of the skin: A randomized controlled trial. Lancet. 1999;354:723-9.

63. Weinstock MA, Bingham SF, Digiovanna JJ, Rizzo AE, Marcolivio $\mathrm{K}$, Hall R, et al. Tretinoin and the prevention of keratinocyte carcinoma (basal and squamous cell carcinoma of the skin): A veterans affairs randomized chemoprevention trial. J Invest Dermatol. 2012;132:1583-90.

64. Gamba CS, Stefanick ML, Shikany JM, Larson J, Linos E, Sims ST, et al. Low-fat diet and skin cancer risk: The women's health initiative randomized controlled dietary modification trial. Cancer Epidemiol, Biomarkers Prev. 2013;22:1509-19.

65. Hughes MC, van der Pols JC, Marks GC, Green AC. Food intake and risk of squamous cell carcinoma of the skin in a community: The Nambour skin cancer cohort study. Int J Cancer. 2006;119:1953-60.

66. Ibiebele TI, van der Pols JC, Hughes MC, Marks GC, Williams GM, Green AC. Dietary pattern in association with squamous cell carcinoma of the skin: A prospective study. Am J Clin Nutr. 2007;85:1401-8.

67. Elmets CA, Viner JL, Pentland AP, Cantrell W, Lin HY, Bailey H, et al. Chemoprevention of nonmelanoma skin cancer with celecoxib: A randomized, double-blind, placebo-controlled trial. J Natl Cancer Inst. 2010;102:1835-44.

68. Darlington S, Williams G, Neale R, Frost C, Green A. A randomized controlled trial to assess sunscreen application and beta carotene supplementation in the prevention of solar keratoses. Arch Dermatol. 2003;139:451-5.

69. Johannesdottir SA, Chang ET, Mehnert F, Schmidt M, Olesen $\mathrm{AB}$, Sorensen HT. Nonsteroidal anti-inflammatory drugs and the risk of skin cancer: A population-based case-control study. Cancer. 2012;118:4768-76.

70. Asgari MM, Chren MM, Warton EM, Friedman GD, White E. Association between nonsteroidal anti-inflammatory drug use and cutaneous squamous cell carcinoma. Arch Dermatol. 2010;146:388-95.

71. Butler GJ, Neale R, Green AC, Pandeya N, Whiteman DC. Nonsteroidal anti-inflammatory drugs and the risk of actinic keratoses and squamous cell cancers of the skin. J Am Acad Dermatol. 2005;53:966-72. 
72. Torti DC, Christensen BC, Storm CA, Fortuny J, Perry AE, Zens MS, et al. Analgesic and nonsteroidal anti-inflammatory use in relation to nonmelanoma skin cancer: A population-based case-control study. J Am Acad Dermatol. 2011;65:304-12.

73. Clouser MC, Roe DJ, Foote JA, Harris RB. Effect of non-steroidal anti-inflammatory drugs on non-melanoma skin cancer incidence in the SKICAP-AK trial. Pharmacoepidemiol Drug Saf. 2009;18:276-83.

74. Caccialanza M, Percivalle S, Piccinno R, et al. Photoprotective activity of oral polypodium leucotomos extract in 25 patients with idiopathic photodermatoses. Photodermatol Photoimmunol Photomed. 2007;23:46-7.

75. Middelkamp-Hup MA, Pathak MA, Parrado C, Goukassian D, Rius-Diaz F, Mihm MC, et al. Oral Polypodium leucotomos extract decreases ultraviolet-induced damage of human skin. J Am Acad Dermatol. 2004;51:910-8.

76. Saliou C, Rimbach G, Moini H, McLaughlin L, Hosseini S, Lee J, et al. Solar ultraviolet-induced erythema in human skin and nuclear factor-kappa-B-dependent gene expression in keratinocytes are modulated by a French maritime pine bark extract. Free Radic Biol Med. 2001;30:154-60.

77. Greenberg ER, Baron JA, Stukel TA, Stevens MM, Mandel JS, Spencer SK, et al. A clinical trial of beta carotene to prevent basal-cell and squamous-cell cancers of the skin. The Skin Cancer Prevention Study Group. N Engl J Med. 1990;323:789-95.

78. Grelck K, Sukal S, Rosen L, Suciu GP. Incidence of residual nonmelanoma skin cancer in excisions after shave biopsy. Dermatol Surg. 2013;39(3 Pt 1):374-80.

79. Swetter SM, Boldrick JC, Pierre P, Wong P, Egbert BM. Effects of biopsy-induced wound healing on residual basal cell and squamous cell carcinomas: Rate of tumor regression in excisional specimens. J Cutan Pathol. 2003;30:139-46.

80. Hacioglu S, Saricaoglu H, Baskan EB, Uner SI, Aydogan K, Tunali S. The value of spectrophotometric intracutaneous analysis in the noninvasive diagnosis of nonmelanoma skin cancers. Clin Exp Dermatol. 2013;38:464-9.

81. Demir H, Isken T, Kus E, Ziya Tan Y, Isgoren S, Daglioz Gorur $\mathrm{G}$, et al. Sentinel lymph node biopsy with a gamma probe in patients with high-risk cutaneous squamous cell carcinoma: Follow-up results of sentinel lymph node-negative patients. Nucl Med Commun. 2011;32:1216-22.

82. Brantsch KD, Meisner C, Schonfisch B, Trilling B, Wehner-Caroli J, Rocken M, et al. Analysis of risk factors determining prognosis of cutaneous squamous-cell carcinoma: A prospective study. Lancet Oncol. 2008;9:713-20.

83. Clark JR, Rumcheva P, Veness MJ. Analysis and comparison of the 7 th edition American Joint Committee on Cancer (AJCC) nodal staging system for metastatic cutaneous squamous cell carcinoma of the head and neck. Ann Surg Oncol. 2012;19:4252-8.
84. Jambusaria-Pahlajani A, Kanetsky PA, Karia PS, Hwang WT, Gelfand JM, Whalen FM, et al. Evaluation of AJCC tumor staging for cutaneous squamous cell carcinoma and a proposed alternative tumor staging system. JAMA Dermatol (Chicago, Ill). 2013;149:402-10.

85. Andruchow JL, Veness MJ, Morgan GJ, Gao K, Clifford A, Shannon KF, et al. Implications for clinical staging of metastatic cutaneous squamous carcinoma of the head and neck based on a multicenter study of treatment outcomes. Cancer. 2006;106:1078-83.

86. Forest VI, Clark JJ, Veness MJ, Milross C. N1S3: A revised staging system for head and neck cutaneous squamous cell carcinoma with lymph node metastases: Results of 2 Australian Cancer Centers. Cancer. 2010;116:1298-304.

87. Breuninger H, Brantsch K, Eigentler T, Hafner HM. Comparison and evaluation of the current staging of cutaneous carcinomas. J Dtsch Dermatol Ges. 2012;10:579-86.

88. Ch'ng S, Clark JR, Brunner M, Palme CE, Morgan GJ, Veness MJ. Relevance of the primary lesion in the prognosis of metastatic cutaneous squamous cell carcinoma. Head Neck. 2013;35:190-4.

89. Lansbury L, Bath-Hextall F, Perkins W, Stanton W, Leonardi-Bee J. Interventions for non-metastatic squamous cell carcinoma of the skin: Systematic review and pooled analysis of observational studies. BMJ. 2013;347:f6153.

90. Bath-Hextall Fiona J, Matin Rubeta N, Wilkinson D, LeonardiBee J. Interventions for cutaneous Bowen's disease. Cochrane Database of Systematic Reviews. 2013(6).

91. Warshauer E, Warshauer BL. Clearance of basal cell and superficial squamous cell carcinomas after imiquimod therapy. J Drugs Dermatol. 2008;7:447-51.

92. Tillman DK Jr., Carroll MT. Topical imiquimod therapy for basal and squamous cell carcinomas: A clinical experience. Cutis cutaneous medicine for the practitioner. Cutis. 2007;79:241-8.

93. Cartei G, Cartei F, Interlandi G, Meneghini G, Jop A, Zingone G, et al. Oral 5 -fluorouracil in squamous cell carcinoma of the skin in the aged. Am J Clin Oncol. 2000;23:181-4.

94. Motley R, Preston P, Lawrence C. Multi-professional guidelines for the management of the patient with primary cutaneous squamous cell carcinoma. London (UK). 2009. Fecha de consulta; febrero de 2014. Disponible en: http://www.bad.org. uk/Portals/ Bad/Guidelines/Clinical\%20Guidelines/SCC\%20 Guidelines\%2oFinal\%20Aug\%2009.pdf.

95. Basal cell carcinoma, squamous cell carcinoma (and related lesions): a guide to clinical management in Australia. Sydney: Cancer Council Australia and Australian Cancer Network; 2008. 

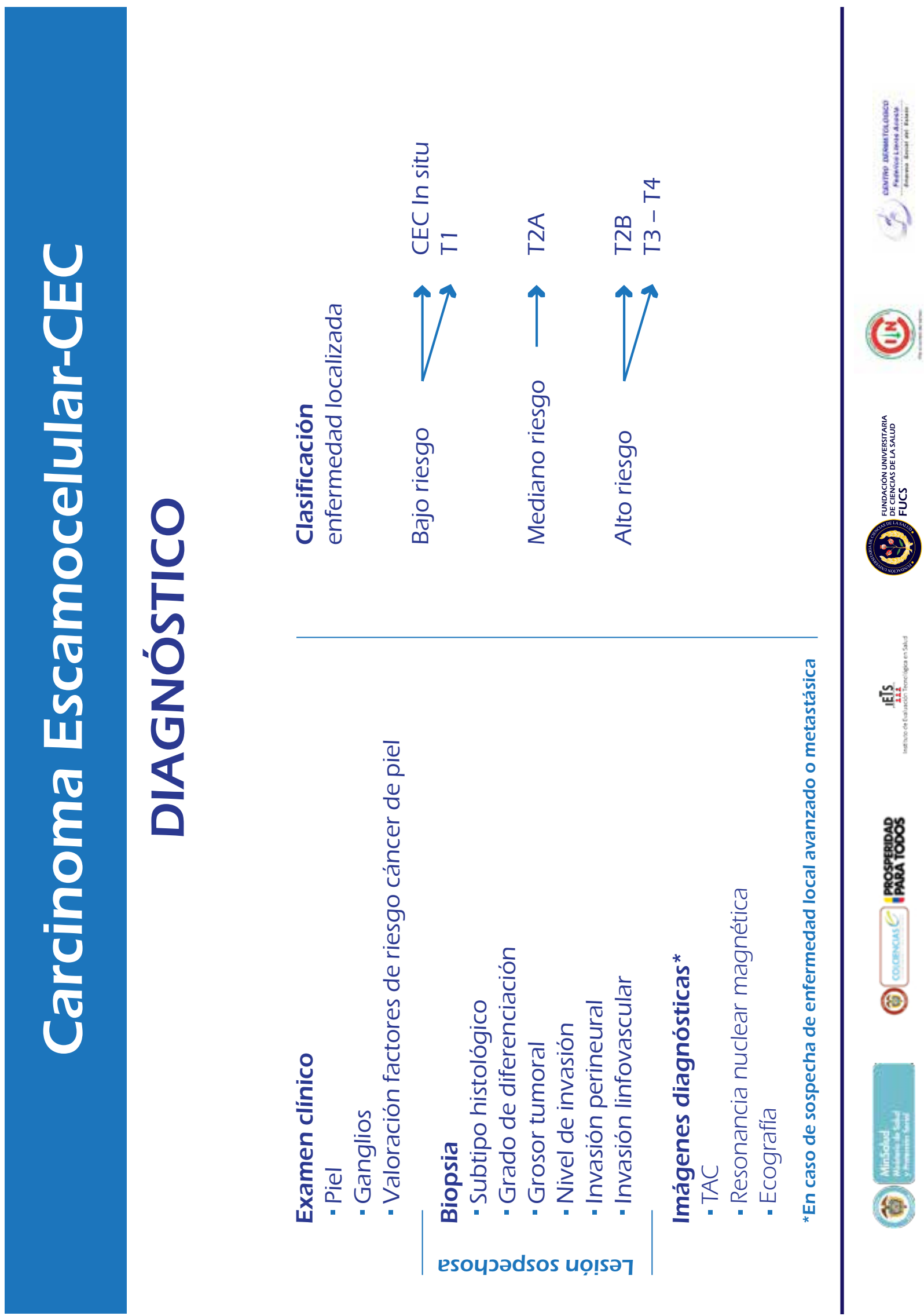

嵫:

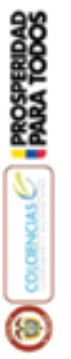

().

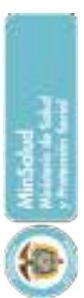

FIGURA 1. Algoritmos de diagnóstico y tratamiento del carcinoma escamocelular. 